\title{
지식요청 동료의 심리적 특권의식에 대한 지식제공자의 인식이 지식은폐 행동에 미치는 영향: 지식은폐 동기의 매개효과와 상사 모니터링의 조절효과*
}

\author{
고 윤 진 \\ 유 태 용 $^{+}$
}

광운대학교 산업심리학과

\begin{abstract}
본 연구의 목적은 지식요청 동료의 심리적 특권의식에 대한 지식제공자의 인식이 지식제공자의 지식은폐 행동에 미치는 영향에서 지식제공자의 지식은폐 동기(사적소유, 손실회피, 부정평가 염려, 부정적 관계)의 매개효과를 확인하고, 상사 모니터링의 조절된 매개효과를 확인하는 데 있다. 가설 검증을 위해 국내 다 양한 기업에서 근무하는 400 명의 직장인을 대상으로 온라인 설문 조사를 실시하였다. 설문 응답을 분석한 결과, 지식요청 동료의 심리적 특권의식에 대한 지식제공자의 인식이 지식제공자의 지식은폐 행동에 미치 는 영향에서 지식제공자의 지식은폐 동기 중 사적소유 동기, 손실회피 동기, 부정평가 염려 동기의 매개 효과가 유의하였다. 그러나 지식은폐 동기 중 부정적 관계 동기의 매개효과는 유의하지 않았다. 상사 모 니터링은 지식요청 동료의 심리적 특권의식과 지식제공자의 지식은폐 행동 간 관계에서 지식제공자의 사 적소유 동기와 손실회피 동기의 매개효과를 조절하여 조절된 매개효과가 유의한 것으로 나타났다. 본 연 구는 지식제공자가 인식하는 지식요청 동료의 심리적 특권의식이 지식제공자의 지식은폐 동기를 높임으 로써 궁극적으로 지식은폐 행동을 더 하도록 한다는 점을 확인하였다. 또한 지식을 요청하는 동료의 심리 적 특권의식이 지식제공자의 지식은폐 동기를 통해 지식은폐 행동을 높이는 과정을 상사 모니터링이 조 절한다는 것을 확인하였다. 구체적으로, 상사의 모니터링 수준이 높을수록 지식요청 동료의 심리적 특권 의식이 지식제공자의 지식은폐 동기(사적소유, 손실회피)를 통해 지식은폐 행동을 높이는 영향을 완화한다 는 점을 확인하였다.
\end{abstract}

주요어 : 지식은폐 동기, 지식은폐 행동, 심리적 특권의식, 상사 모니터링

* 보다 나은 논문이 되도록 귀중한 조언을 해주신 심사위원들께 감사드립니다.

† 교신저자 : 유태용, 광운대학교 산업심리학과, Tel: 02-940-5422, E-mail: tyyoo@kw.ac.kr 
'지식'은 경쟁적이고 급변하는 경영 환경에 서 조직에 경쟁적 이점을 제공하는 소중한 자 원이다(Spender \& Grant, 1996). 많은 기업들은 지식을 소중한 자산으로 인식하고, 기업 경쟁 력 확보를 위해 지식경영을 적극적으로 도입 하였다. 그러나 지식경영의 효과는 투자한 노 력에 비해 낮았는데, 포춘지 선정 500대 기업 들을 조사한 결과, 대부분의 기업들이 지식공 유에 실패하여 연간 최소 315 억 달러의 손해 를 본 것으로 나타났다(Babcock, 2004). 지식공 유가 실패하지 않고 활성화되기 위해서는 학 습지향적인 조직문화, 관리적 지원, 보상, 팀 의 특성, 사회적 네트워크 등의 선행요인이 필요하다(Wang \& Noe, 2010). 많은 기업에서는 지식공유의 실패 원인을 이러한 선행요인들 가운데서 찾고 있지만, 가장 중요한 것은 지 식제공자의 노력과 의도라고 할 수 있다. 지 식공유는 지식제공자의 의지에 따라 공유되는 지식의 양과 질이 달라질 수 있고, 아무리 좋 은 시스템과 관리 방식을 가지고 있어도 어떤 특정한 개인이 의도적으로 지식을 독점하고 공유하지 않는다면 지식경영의 효과는 낮을 수밖에 없기 때문이다(Choi, 2002).

조직 구성원들이 의도적으로 지식을 주지 않거나 숨기려는 시도나 행동을 지식은폐 (knowledge hiding)라고 한다(Connelly, Zweig, Webster, \& Trougakos, 2012). 지식은폐 행동은 얼버무리기(evasive hiding), 합리화하기(rationalized hiding), 바보같이 굴기(playing dumb)의 3 가지 행동 유형으로 분류할 수 있다. 얼버무리기는 부정확하고 완전하지 않은 정보를 제공하는 것을 의미하는데(Connelly et al., 2012), 상대방 을 속이려는 '기만적인 의도'가 포함되어 있어 가장 악의적인 행동으로 볼 수 있다. 합리화 하기는 기만적인 의도가 포함되어 있지 않지
만, 요청한 지식을 전달할 수 없는 이유를 제 시하고 그 정당함을 설명하는 행동이다. 바보 같이 굴기(playing dumb)는 지식을 모르는 척하 는 행동으로 요청한 지식에 대해 답변해 줄 지식이 없거나 복잡한 문제를 해결해야 하는 데 그 해결 방법을 알지 못할 때 발생할 수 있다(Antes \& Mumford, 2012).

지식은폐는 지식경영의 효과를 낮추는 요인 중 하나로서 조직과 대인관계에 심각한 위험 을 초래할 수 있다. 조직 차원에서는 조직의 목표 달성을 위한 경험, 노하우, 아이디어 등 이 공유되는 역동적인 상호작용이 이루어지지 않아 조직학습을 저해할 수 있고(Connelly et al., 2012), 동료와 팀의 창의적 수행과 혁신행 동을 낮출 수 있다(Bogilović, Černe \& Škerlavaj, 2017; Černe, Nerstad, Dysvik, \& Škerlavaj, 2014; Černe, Hernaus, Dysvik, \& Škerlavaj, 2017; Rhee \& Choi, 2017). 대인관계 측면에서도 지식은폐 는 부정적인 영향을 줄 수 있는데, 지식은폐 행동에는 단순히 지식을 숨기는 것만이 아니 라 동료를 속이려는 의도가 내포되어 있기 때 문에 지식요청자와 지식제공자 간에 상호 불 신을 높이고 관계를 손상시킬 수 있다(Connelly \& Zweig, 2015). 이처럼 지식은폐는 조직과 대인관계에 심각한 영향을 주어 부정적인 결 과를 가져올 수 있기 때문에 조직 차원에서 관리가 필요하다(Connelly, Černe, Dysvik, \& Škerlavaj, 2019).

지식은폐의 선행요인은 개인특성, 지식특성, 과업특성, 대인관계특성, 조직특성으로 구분해 볼 수 있다. 먼저, 개인특성 측면에서 높은 신 경증을 가진 개인은 지식전달 과정에서 받는 불안과 스트레스로 인해 지식은폐(예, 바보처 럼 굴기 행동) 수준이 높아지고(Demirkasimoglu, 2016), 냉소주의적 개인은 타인과 정서적 신뢰 
형성에 어려움을 갖기 때문에 지식요청 동 료를 돕는 것을 거부한다(Aljawarneh \& Atan, 2018). 또한, 목표 지향적인 특성을 가진 개인 은 지식 전달이 곧 경쟁적인 이점 상실로 이 어진다고 인식하기 때문에 지식은폐 수준이 높아진다(Cai \& Wen, 2018). 지식특성 측면에 서는 지식에 대한 통제력, 시간과 에너지의 투자 정도, 지식에 대한 친밀함, 지식의 복잡 성과 지식의 관련성이 지식은폐 수준을 높인 다(peng, 2013; Connelly et al., 2012). 과업특성 측면에서 협력적 목표 상호의존성은 지식공유 를 높이고 경쟁적 목표 상호의존성은 지식은 폐 수준을 높인다(Bavik, 2015). Hernaus, Cerne, Connelly, Vokic과 Škerlavaj(2019)은 개인의 경쟁 심이 지식은폐 행동(예, 얼버무리기) 수준을 높이지만, 협력적인 과업관계를 의미하는 과 업 상호의존성이 경쟁심과 지식은폐 행동 간 의 관계를 완화시킨다는 점을 확인하였다.

대인관계 특성 측면에서는 상대방에 대 한 불신(distrust)이 지식은폐 행동을 높이며 (Connelly et al., 2012), 불신으로 인해 발생한 호혜적 지식은폐는 순환적 지식은폐로 이어질 수 있다(Černe et al., 2014; Serenko \& Bontis, 2016). 지식은폐는 상사와 부하 관계에서도 발 생하는데, 무례하고 적대적인 상사의 비인격 적 감독은 구성원들의 지식은폐 행동 수준을 높인다(Khalid et al., 2018). 특히, 전위 공격성 이론(displaced aggression theory: Dollard, Doob, Miller, Mowrer, \& Sears, 1939)에 따라, 상사에게 적대적인 대우를 받은 구성원들은 동일하게 상사에 대한 공격으로 대응하지 않고, 상사가 아닌 다른 동료들에게 지식은폐 행동을 보인 다. 반면, 상사의 윤리적 리더십은 조직 구성 원들 간 지식은폐 수준을 낮춘다. 구성원들은 윤리적인 리더의 도덕적 가치를 학습하고 내
재화함에 따라 지식은폐 의지를 줄이기 때문 이다(Tang et al., 2015). 조직특성 측면에서는 조직 공정성에 대한 인식이 높을 때 지식은폐 수준은 낮아지며(Abubakar, Elrehail, Alatailat, \& Elçi, 2019), 조직 내 정치 지각은 지식은폐를 높여 개인의 창의적 수행을 감소시킨다(Malik, Shahzad, Raziq, Khan, Yusaf, \& Khan, 2019). 또한, 조직 내 부정적 가십(negative workplace gossip)은 직무 압박에 의해 발생된 자원손실을 회복하기 위해 지식은폐 수준을 높인다(Yao, Luo, \& Zhang, 2020).

지금까지 지식은폐의 다양한 선행요인을 확 인하는 연구들이 수행되었지만, 본 연구에서 는 지식을 요청하는 동료의 심리적 특권의식 에 대한 지식제공자의 인식을 선행요인으로 다루고자 한다. 업무 환경을 구성하는 요인들 중에 '동료'는 다른 구성원의 태도와 행동에 영향을 주는 매우 중요한 요인이다(Bommer, Miles, \& Grover, 2003). 조직 구성원들은 동료 와의 상호작용을 통해 정서적, 물리적 자원을 주고받으며(Ferris \& Mitchell, 1987), 모방, 경쟁 등을 통해 태도와 행동을 결정한다(Chiaburu \& Harrison, 2008). 동료가 주는 영향력은 긍정적 인 면과 부정적인 면 모두를 포함하고 있다. 긍정적인 측면에서 동료의 사회적 지원은 개인 의 스트레스를 감소시키고(Viswesvaran, Sanchez, \& Fischer, 1999), 업무 스트레스로부터 발생하 는 직무 소진을 예방할 수 있다(Halbesleben, 2006). 또한, 동료에 대한 신뢰는 협력과 팀워 크 수준을 높이며(McAllister, 1995), 직무 만족, 조직 몰입 등 직무태도에도 긍정적인 영향을 준다(Dwivedi, 1983). 반면 동료로 인해 발생한 좌절감은 수치심, 분노와 같은 부정적 정서 상태를 유발함으로써 정서 및 행동에 대한 통 제력을 저하시킬 수 있다(Joiner, 2005). 
지식을 주고받는 과정에 있어서도 '동료'의 존재는 중요하다. 지식을 요청하는 요청자의 대부분은 상호의존적으로 일하고 있는 동료가 될 가능성이 높기 때문이다. 지식을 공유하는 행동은 도움행동의 하나로 볼 수 있는데, 대부분의 도움행동에는 업무 관련 도움이나 조언, 정보를 요청하는 '요청자'가 존재하며 (Kaplan \& Cowen, 1981), 구성원들은 도움 요청 에 대해 응답하기 전에 요청자인 동료가 자신 의 도움을 받을 만한 자격이 있는지 검토하게 된다(Bolino, 1999). 동료의 요청에 도움을 주는 것은 역할 외 수행이기 때문에 동료의 부탁을 들어줄지 여부는 도움을 전달할 행위자의 선 택에 달려있다. 따라서 도움을 받고자 하는 요청자가 평소 보여주는 행동과 태도가 긍정 적이라면 도움에 대해 긍정적으로 검토하겠지 만, 요청자가 평소에 보이는 행동과 태도가 부정적이라면 이를 거부할 수도 있다. 도움행 동의 하나인 지식공유도 유사한 방식으로 요 청자의 자격을 검토할 수 있다. 지식을 전달 하는 것이 과업에서 요구하는 규범이나 필수 적인 행동이 아니기 때문에 지식전달 여부는 지식요청자가 보여주는 태도와 행동에 의해 결정되며, 지식요청자가 보여주는 특성이 부 정적일 경우 동료에 대한 불신으로 이어져 지식 전달을 거부할 수 있다(Connelly et al., 2012).

Connelly 등(2012)은 지식요청자의 특성은 지 식은폐의 중요한 선행변인이므로 지속적인 탐 색이 필요하다고 제언하였다. 또한 Connelly 등 (2019)은 지식요청자와 지식제공자는 단순히 정보를 주고받는 것 이상으로 어떤 특성의 사람이 지식을 요청하는지에 따라 지식공유 행동과 결과가 달라질 수 있다고 설명하였다. Tang, Bavik, Chen과 Tjosvold(2015)도 지식은폐
는 지식을 요청하는 사람의 특성에 영향을 받 기 때문에 지식요청 대상에 대한 연구가 필요 하다고 주장하였다. 본 연구에서 다루고자 하 는 지식요청자의 특성은 심리적 특권의식이다. 심리적 특권의식이 높은 사람들은 특별한 대 우나 보상을 받아야 한다고 일관되게 믿는다 (Harvey \& Harris, 2010). 지나친 특권의식을 가 진 구성원들은 지나치게 자기중심적인 행동을 보여 타인의 자원을 불공정하게 취득하려고 하고(Levine, 2005), 다른 사람의 지식을 왜곡 되게 활용하거나 폄하하고 무시하기도 한다 (Harvey \& Martinko, 2009). 업무 관련 지식은 오랜 시간 축적해온 자신만의 업무 노하우이 므로, 제공자는 요청자가 지식의 가치를 폄하 하거나 왜곡된 사용을 하도록 놔둘 수는 없을 것이다. 본 연구에서는 지식제공자의 지식은 폐 행동을 유발하는 선행요인으로 지식요청 동료의 심리적 특권의식에 대한 지식제공자의 인식을 다루고자 한다.

또한 본 연구에서는 지식요청 동료의 심리 적 특권의식에 대한 지식제공자의 인식이 지 식제공자의 지식은폐 행동에 미치는 부정적인 영향을 줄이기 위한 상사 모니터링 행동의 조 절효과를 확인하고자 한다. 상사의 행동은 구 성원들에게 본보기가 될 수 있으며 규범을 형 성한다. 특히, 상사의 모니터링은 상사가 구성 원들의 성과에 대한 보상을 나누는 데 있어서 공정성을 유지할 수 있게 하는 중요한 요인이 다. 상사의 모니터링은 부하들에게 피드백을 제공하고 과업수행을 조정하며, 공정한 보 상 결정을 위한 정보를 수집하기 위한 기능 을 수행한다(Alder \& Ambrose, 2005). 공정한 결정을 내리는 데 있어 정확한 정보 수집은 중요한 부분이라고 할 수 있는데, Niehoff와 Moorman(1993)은 상사의 모니터링이 절차공 
정성 지각에 긍정적인 영향을 준다고 보고하 였다.

상사의 모니터링은 구성원들의 공정성 인식 을 높여 지식은폐를 줄여줄 수 있다. 지식요 청자가 부정적인 행동으로 동료들에게 피해를 주더라도 상사가 정확하게 관찰하여 공정하 게 처벌해줄 것이라 기대하기 때문이다. 공정 성 휴리스틱 이론(justice heuristic theory: Lind, 2001)에 따라, 조직 공정성에 대한 인식이 높 으면 지식공유를 촉진할 수 있다. 지식 전달 여부를 고민하고 있는 상황에서 상사가 구성 원들을 공정하게 파악하고 모든 구성원들을 공정하게 처우할 것이라고 인식한다면, 지식 을 전달함으로써 발생될 불공정성에 대한 불 안감이 감소하게 되어 지식을 숨기려는 의도 가 줄어들 것이다. 또한 지식을 전달하면서 얻게 될 공정한 인정과 보상은 오히려 지식공 유를 촉진할 수 있다. 따라서 상사의 모니터 링은 지식요청자의 부정적 특성으로 인해 유 발되는 지식제공자의 지식은폐 행동을 줄일 수 있을 것이다.

기존 연구에서는 상사의 행동으로 상사의 비인격적 감독, 상사의 지식은폐 행동이 구성 원의 지식은폐 행동에 미치는 영향을 다루었 지만(Khalid, Bashir, Khan, \& Abbas, 2018; Tang et al., 2015; Arain, Bhatti, Ashraf, \& Fang, 2020), 상사의 행동을 조절변인으로 다룬 연구가 부 족한 실정이다. 따라서 본 연구에서는 지식요 청 동료의 심리적 특권의식에 대한 지식제공 자의 인식이 지식은폐에 미치는 부정적인 영 향을 줄이기 위한 상사 모니터링 행동의 조절 효과를 확인하여 실무적 시사점을 제공하고자 한다.

\section{지식은폐 동기}

지식은폐 동기는 지식은폐 행동을 유발하는 네 가지 동기 유형을 의미한다(Ko \& Yoo, 2020). 지식은폐 동기의 첫 번째 요인은 사적 소유 동기로, 지식제공자가 지식을 자신의 사 적 소유물로 여기고 어렵게 얻은 지식을 쉽게 공유하지 않으려는 동기를 의미한다. 심리적 주인의식 이론(psychological ownership theory: Pierce, Kostova, \& Dirks, 2001)에 따라, 심리적 주인의식은 조직 내 유형의 사물뿐만 아니라 무형의 아이디어나 업무 목표 등에서도 발생 될 수 있다(Pierce \& Jussila, 2010). 특히, 지식과 같은 무형의 대상은 다른 사람들이 쉽게 소유 권을 주장할 수 있는 위험이 있어 소유에 대 한 불확실성으로 인한 불안이 더욱 높아지게 된다. 따라서 개인이 지식에 대해 느끼는 불 안은 자신이 가진 지식에 대한 통제력을 유지 하기 위한 지식은폐 행동으로 이어진다.

두 번째 손실회피 동기 요인은 지식요청자 와의 경쟁 관계에서 지식을 빼앗기지 않으려 는 지식제공자의 동기를 의미한다. 사회비교 이론(social comparison theory: Festinger, 1954)에 따르면, 개인은 자신의 능력, 생각과 의견, 행 동, 태도 등을 다른 사람들과 비교하고, 이를 토대로 자기 스스로를 평가한다. 특히, 자기 고양 동기를 가진 사람은 다른 사람과 비교하 여 자신에게 더 좋은 평가를 하고자 노력하는 데, 자신보다 수행 수준이 떨어지거나 열악한 환경에 있다고 생각되는 다른 사람과 비교하 여 자신의 현재 수준에 안도감을 느끼려고 한다. 조직 내 지식은 경쟁적인 이점을 얻을 수 있는 매우 가치 있는 자원이다(Jarvenpaa \& Majchrzak, 2008). 동료가 업무에 필요한 지식이 없다는 것은 자신보다 불리한 환경에 처해있 
다는 것을 의미하므로 자신을 경쟁적 우위에 놓기 위해 지식을 전달하지 않는다.

세 번째 요인인 부정평가 염려 동기 요인은 지식에 대한 내용의 불확실성과 지식요청자의 피드백에 대한 두려움으로 지식제공자가 지식 을 숨기려는 동기를 의미한다. 자기조절초점 이론(self-regulatory focus theory: Higgins, 1997)에 따라, 예방초점을 지닌 사람은 위험한 상황을 회피하여 부정적인 결과(예, 처벌)를 감소하는 데 목표를 둔다(Kark \& Van Dijk, 2007). 따라 서 지식요청 상황에서도 자신의 지식을 숨김 으로써 자신의 약점을 드러내지 않고 보다 안 전한 환경에 있다고 느끼기 때문에 모든 정보 를 감추려고 한다(Černe et al., 2014). 따라서 자신에 대한 부정적인 평가를 염려하는 사람 은 현재상태의 유지를 선호하고 부정적 결과 에 민감하므로 지식공유를 통해 얻게 되는 부정적 평가를 회피하기 위해 지식을 숨기려 한다.

네 번째 지식은폐 동기 요인은 부정적 관계 동기 요인으로 지식요청자에 대한 부정적인 감정으로 인해 지식제공자가 보복적인 의도를 갖고 지식을 전달하지 않으려는 동기를 의미 한다. 사회 교환 이론에 기반을 둔 호혜성 규 범에 따라(norm of reciprocity: Gouldner, 1960), 자신에게 부당한 대우를 한 상대방에게는 같 은 방식으로 보복행동을 하려고 한다(Mitchell \& Ambrose, 2007). 특히 조직에서 동료로부터 무례함을 경험한 구성원은 적대적인 감정을 교환하게 되는데, 이러한 감정은 무례함에 대 한 보복 행동으로 이어질 수 있다(Anderson \& Pearson, 1999). 따라서 이처럼 무례한 동료가 자신에게 지식을 요청하는 상황에서는 지식요 청자와의 관계가 공정하지 않다고 인식하거나 적대감을 가지고 있기 때문에 요청받은 지식
을 숨기고 은폐하려 할 것이다.

지식요청 동료의 심리적 특권의식과 지식제공 자의 지식은폐 행동 간 관계에서 지식은폐 동 기의 매개효과

심리적 특권의식은 '보상에 대한 기대'에 초점을 두는 것으로써 실제 성과와 관계없이 자신이 다른 사람들보다 더 많이 받을 만하 고 더 많은 자격이 있다고 여기는 것이다 (Campbell et al., 2004). 따라서 심리적 특권의 식이 높은 개인은 과도하게 자신을 높게 평가 하고 보상에 대한 비현실적인 기대를 하는 경 향이 있으며(Harvey \& Martinko, 2009; Harvey, Harris, Gillis, \& Martinko, 2014), 관계 측면에서 도 사람들이 나에게 무조건적으로 호의를 베 풀 것이라 생각하며 타인의 자원을 착취하려 는 특징을 보인다(Emmons, 1987).

많은 연구자들은 주로 개인의 심리적 특권 의식을 자기 고양적 편향(self-serving attributional bias)을 통해 설명한다(Kelley, 1973; Weiner, 2004). 자기 위주 귀인 편향을 가진 개인은 긍 정적인 결과에 대해서는 자신의 공으로 여기 지만, 부정적인 상황에 직면하면 현재의 결과 가 불공정하거나 바람직하지 않은 것처럼 여 긴다. 자기 위주 귀인 편향에 따라 심리적 특 권의식이 높은 사람은 자신의 능력에 대해 부 풀려진 견해를 갖고 있기 때문에 긍정적인 사 건에 대해서는 자신의 노력 때문이라고 여기 지만(Snow, Kern, \& Curlette, 2001), 부정적 사 건이나 결과에 대해서는 잘못을 외부의 탓으 로 돌리며 그들이 갖고 있는 자격과 부풀려진 자기 인식을 회복하고 보호하려고 한다(Harvey \& Martinko, 2009; Harvey \& Harris, 2010). 따라 서 심리적 특권의식이 높은 개인은 부정적인 
결과에 대해 분노와 좌절을 하게 되고 이러한 부정적인 정서를 갖게 한 동료들을 비난하는 경향이 있으며, 결과적으로 조직 내에서 부 정적인 결과를 초래할 수 있다(Weiner, 2004; Harvey et al., 2014).

이러한 심리적 특권의식의 행동 특성을 바 탕으로, 지식을 요청하는 동료가 심리적 특권 의식을 지니고 있는 경우에는 지식제공자의 네 가지 지식은폐 동기 수준을 높여 궁극적으 로 지식은폐 행동이 나타날 것이라고 예상할 수 있다. 첫 번째로 심리적 주인의식 이론에 따르면, 개인은 어떠한 대상에 대해 잘 알고 있거나 통제 가능할 때, 그리고 많은 시간과 에너지를 투자했을 때, 대상에 대한 소유의 감정을 느낀다(Pierce, et al., 2001). 이러한 소유 의 대상은 조직 내 유형의 사물뿐만 아니라 무형의 대상도 될 수 있으므로, 개인은 자신 의 지식에 대해서도 소유감을 지니게 된다. 특히 구성원들은 자신이 남들보다 더 잘 알고 있거나, 오랜 시간 숙련을 통해 지식을 얻었 을 때 그러한 지식에 대해 더 높은 소유감을 느낀다. 심리적 특권의식이 높은 동료는 다른 사람이 가진 지식에 대해 그 가치를 무시하 거나 폄하할 수 있으며 왜곡된 방식으로 지식 을 활용할 가능성이 있다(Harvey \& Martinko, 2009). 따라서 심리적 특권의식이 높다고 인식 한 동료가 지식을 요청하면, 지식제공자는 자 신의 소중한 지식이 무시되거나 왜곡된 방식 으로 활용될 것을 막기 위해 지식을 전달하지 않으려 할 것이다. 따라서 심리적 특권의식이 높다고 인식한 동료가 지식을 요청하면 지식 제공자의 사적소유 지식은폐 동기가 높아져서 지식은폐 행동이 나타날 가능성이 크다.

두 번째로, 심리적 특권의식이 높은 사람들 은 받은 정보조차 자기중심적으로 정보를 해
석하고 왜곡하여 습득하는데, 이렇게 정보를 가공하는 이유는 조직에서의 생활이나 개인 생활을 성공적으로 만들어나가기 위한 방법 으로 활용하기 위해서다(Harvey \& Martinko, 2009). 가공된 정보는 긍정적인 이미지를 구축 하고 이를 유지 및 보호하기 위해 활용하기도 하고, 주변 동료를 과소평가하며 지위를 높이 고 경쟁적 우위를 얻으려는 데 활용하기도 한 다(Ohbuchi \& Fukushima, 1997). 심리적 특권의 식이 높다고 인식한 동료에게 지식을 전달하 는 것은 곧 그들에게 경쟁적 우위를 제공하는 행동이 될 수 있다. 따라서 심리적 특권의식 이 높다고 인식한 동료로부터 지식을 요청받 는 경우에 지식제공자는 경쟁에서 피해를 보 지 않으려는 손실회피 동기가 높아져서 지식 은폐 행동이 나타날 가능성이 크다.

세 번째로, 평가-불안-회피이론(appraisalanxiety-avoidance theory; Milgram, Mey-Tal, \& Levison, 1998)에 따라 심리적 특권의식이 높다 고 인식한 동료로부터 지식을 요청받는 경우 에 지식제공자는 자신이 제공한 지식으로 인 해 자신이 평가 받거나 비판 받게 되는 상황 이 발생할 가능성이 있어서 지식 제공을 꺼릴 수 있다. 심리적 특권의식이 높은 개인은 자 신에게 돌아오는 대우에 대해 관심이 있을 뿐 만 아니라, 타인의 성공에 대해서는 인정하지 않는 경향이 있어 타인이 노력을 기울여 작 업한 결과물에 대해 의도적으로 부정적인 평 가를 전달하기도 한다(Harvey \& Harris, 2010). Reidy, Zeichner, Foster와 Martinez(2008)는 심리적 특권의식을 나르시시즘의 자기애적 특성 중 하나로 설명하며 이러한 개인의 특성은 공격 성과 관련이 높다는 것을 밝혔는데, 자신이 마땅히 받아야 하는 대우와 보상 등을 실제보 다 크게 생각하기 때문에 동료가 원하는 수준 
의 지식을 제공하지 못했을 때 공격적인 행동 이 나타날 수 있으며 이러한 행동은 동료와의 갈등을 일으키는 원인이 될 수 있다고 하였다. 따라서 심리적 특권의식이 높다고 인식한 동 료에게 지식을 제공한 후에 돌아오게 되는 자 신에 대한 부정적인 평가와 비판에 대한 염려 로 인해 지식제공자의 부정평가 염려 지식은 폐 동기가 높아져서 지식은폐 행동이 나타날 가능성이 크다.

마지막으로, 사회 교환 이론에 따라 지식요 청자의 심리적 특권의식은 지식제공자의 보복 적 의도를 포함하는 부정적 관계 지식은폐 동 기를 유발할 수 있다. 심리적 특권의식이 높 은 사람은 자신을 객관적으로 바라보지 않고 과대평가하므로, 대부분의 상황을 자신이 기 대한 것보다 낮은 대우를 받는 상황으로 인식 한다(Snow et al., 2001). 또한 기대한 정보를 받 지 못하는 상황에 대해 분노하고 공격적인 행 동을 보이며, 남들보다 특별한 보상을 받지 못했을 때 부정적인 수단을 써서라도 보상을 추구하기 때문에 조직과 동료들에게 피해를 줄 수 있다(Campbell et al., 2004). 다른 사람 들의 성과를 인정하거나 자신의 실패를 인 정하는 것에 대해 어려움을 가지며(Exline,

Baumeister, Bushman, Campbell, \& Finkel, 2004), 나쁜 결과나 잘못을 동료에게 귀인하기 때문 에 동료들과 갈등을 경험하기도 한다(Harvey \& Martinko, 2009). 따라서 심리적 특권의식이 높 다고 인식한 동료가 지식을 요청하는 경우에 지식제공자는 평소에 그 동료와의 부정적인 관계로 인해 지식요청자의 요청을 거절하고 지식을 숨기려 할 가능성이 크다. 이러한 선 행연구와 추론을 바탕으로 다음과 같은 가설 을 설정하였다.
가설 1-1. 지식제공자의 사적소유 동기는 지 식요청 동료의 심리적 특권의식과 지식제공자 의 지식은폐 행동 간 관계를 매개할 것이다.

가설 1-2. 지식제공자의 손실회피 동기는 지 식요청 동료의 심리적 특권의식과 지식제공자 의 지식은폐 행동 간 관계를 매개할 것이다.

가설 1-3. 지식제공자의 부정평가 염려 동기 는 지식요청 동료의 심리적 특권의식과 지식 제공자의 지식은폐 행동 간 관계를 매개할 것 이다.

가설 1-4. 지식제공자의 부정적 관계 동기는 지식요청 동료의 심리적 특권의식과 지식제공 자의 지식은폐 행동 간 관계를 매개할 것이다.

\section{상사 모니터링의 조절된 매개효과}

조직에서 상사는 구성원들이 어떠한 방식으 로 일하고 행동할지 통제하는 데 영향을 주는 가장 중요한 요인이다(Komaki, 1986). 상사는 부하의 업무 목표를 설정하고, 보다 효과적인 업무처리 방법을 가르치며, 적절한 행동모델 이 되고, 성과에 대한 적절한 보상과 처벌을 결정한다(Campbell, 1990). 구성원들은 이러한 상사의 모습을 보고 과업을 어떠한 방식으로 수행할지, 어떠한 의사결정이 바람직한지 판 단할 수 있다. 특히, 상사의 성과 모니터링은 조직 통제 시스템의 주요한 요소로서, 구성원 들의 수행을 관찰하고 자료를 수집하고 성과 를 검토하는 것을 의미한다(Flamholtz, 1979).

많은 리더십 연구는 상사 모니터링을 구성 원들의 수행을 관리하는 효과적인 행동으로 간주하고(Komaki, 1986; Luthans, Hodgetts, \& Rosenkrantz, 1988; Yukl, 1989), 부하의 수행과 관리 효과성에 긍정적인 영향을 준다는 것 을 밝혔다(Komaki, 1986; Komaki, Desselles, \& 
Bowman, 1989; Larson \& Callahan, 1990). 상사 모니터링은 과업 지향적 행동으로 부하직원 의 수행에 대한 정보를 얻기 위한 활동인데 (Komaki, Zlotnick, \& Jensen, 1986), 이러한 정보 는 부하 직원에게 수행에 대한 피드백을 제공 할 때 활용하고(Flamholtz, 1979), 과업 추진 과 정에서 부하직원과 커뮤니케이션하는 데 도움 을 줄 수 있다(Larson \& Callahan, 1990).

상사 모니터링은 보상을 결정하는 과정에서 공정성을 유지하기 위한 최우선의 대안 중 하 나이다. 모니터링 과정은 직무수행을 관찰하 고 수행결과를 점검하며, 주기적인 미팅을 통 해 부하들이 과업 진행 상황을 구두로 보고하 도록 하고, 직무수행과 관련된 핵심지표를 요 약한 보고서 등에 대한 검토 활동이다(Larson \& Callahan, 1990). 따라서 효과적인 관리자는 직무수행을 공정하고 정확하게 모니터링하고, 수행성과를 평가하여 그에 합당한 보상을 제 공할 수 있다. 이와 반대로 비효과적인 관리 자는 직무수행을 일관성 없이 모니터링하며, 성과와 무관한 보상을 한다(Komaki et al., 1986). 따라서 상사의 모니터링은 보상을 공정 하게 제공하기 위해 정확한 정보를 얻는 중요 한 과정이기 때문에 구성원들의 공정성에 대 한 인식에 영향을 미칠 수 있다.

대부분의 조직은 팀제로 조직을 구성하여 공동의 목표를 설정하고 상호의존적으로 과업 을 수행하도록 하고 있다. 심리적 특권의식이 높은 사람들은 특별한 대우와 보상을 받아야 한다고 믿고(Harvey \& Harris, 2010), 자기중심 적인 행동을 보여 타인의 자원을 불공정하게 취득하려고 한다(Levine, 2005). 공정성 휴리스 틱 이론에 따라, 불공정한 환경에 대한 인지 적 평가는 개인행동에 영향을 준다(Walster, Erscheid, \& Walster, 1973). 따라서 팀 성과에
기여하지 않는 동료의 특권적 행동은 팀 구성 원들의 불공정성 인식을 높여 비협조적인 행 동으로 이어지게 할 수 있다. 조직 내 상사는 팀 구성원들의 수행을 관리하는 책임을 가지 고 있기 때문에 심리적 특권의식이 높은 개인 을 통제하여 팀 구성원들의 불공정성 인식을 낮추는 개입이 필요하다.

상사 모니터링은 불공정성에 대한 구성원들 의 불안을 낮추고 지식은폐 의도를 줄일 수 있다(Komaki, 1986). Lind(2001)는 구성원들이 조직이나 동료들에게 협력적인 행동을 할 것 인가를 의사결정 함에 있어 공정성은 중요한 요소라고 하였으며, Tyler와 Lind(1992)도 공정 한 대우를 받는다고 인식하면 공정성 휴리스 틱이 발생하여 협력적인 행동을 한다고 하였 다. Park, Lee, Son, Kim과 Yun(2011)도 구성원 들은 조직 공정성에 대한 인식이 높으면 지식 공유 수준을 높인다고 하였다.

상사 모니터링은 공정성 인식을 높여 동료 에 대한 처벌 의무감도 감소시킬 수 있다. 구 성원들은 동료가 부정적인 행동(예, 무례)을 할 때 조직에서 공정하게 관리하고 처벌해주 길 기대한다. 조직이 동료의 부정적 행동에 관용을 보인다면, 구성원들의 불신은 냉소주 의로 이어지고 스스로 동료를 처벌하려고 한 다. 처벌은 유사한 방식의 부정적 행동이 될 수 있는데, 동료가 특권적 행동으로 다른 구 성원들의 자원을 빼앗으면 구성원들도 자신이 가지고 있는 자원을 전달하지 않으려는 유사 한 행동을 할 수 있다. 상사 모니터링은 합의 한 대로 업무를 수행하지 않고 성과를 저해하 는 구성원들을 관리하는 예방적 개입 활동이 다(Larson \& Callahan 1990). 따라서 팀 성과를 방해하고 자원을 빼앗으려는 구성원들을 관리 할 수 있으며, 스스로 동료의 특권적 행동을 
처벌하려는 팀 구성원들의 부정적 행동을 예 방할 수 있다.

이러한 선행연구를 종합해보면, 모니터링 을 통해 공정성을 유지하려는 상사의 행동은 구성원들의 협력적 태도와 행동에 영향을 주 고 지식공유를 유발할 수 있다. 따라서 상사 의 모니터링은 공정성 인식을 높여 구성원들 의 지식은폐 수준을 낮출 것이라고 예상할 수 있다.

지식은폐를 감소시키는 상사의 모니터링 역 할을 구체적으로 제시하면 다음과 같다. 먼저, 지식요청 동료의 심리적 특권의식에 대한 지 식제공자의 인식이 사적소유 동기를 통해 지 식은폐 행동 수준을 높이는 관계를 상사 모니 터링이 약화시킬 것이다. 사적소유 지식은폐 동기는 지식의 가치를 높게 인식하고 오랜 노 하우가 담긴 자신의 지식을 공유하지 않으려 는 것이다. 하지만 자신이 가치 있는 지식을 제공하는 것에 대해 상사가 공정한 보상과 대 우를 해준다면 사적소유 동기가 감소해서 궁 극적으로 지식은폐 행동이 줄어들 가능성이 있다. 또한 상사가 심리적 특권의식이 높은 동료를 모니터링하여 부정적 행동에 대해 징 계 또는 처벌할 수 있으므로, 자신이 제공한 지식을 동료가 왜곡되거나 부정적으로 활용할 가능성이 낮아지게 된다. 따라서 자신이 지식 을 제공함으로써 얻게 될 보상에 대한 기대감 과 동료의 부정적 행동에 대한 상사의 처벌은 사적소유 지식은폐 동기를 감소시켜서 궁극적 으로 지식은폐 행동 수준을 낮출 수 있을 것 이다.

둘째, 지식요청 동료의 심리적 특권의식에 대한 지식제공자의 인식이 손실회피 동기를 통해 지식은폐 행동 수준을 높이는 관계를 상 사 모니터링이 약화시킬 것이다. 공정성 휴리
스틱 이론에 따라, 상사의 모니터링 행동은 지식은폐 행동을 예방할 수 있다. 구성원들은 상사가 적극적으로 수행을 모니터링 할수록 성과에 대한 정확한 정보를 수집한다고 여긴 다(Larson \& Callahan, 1990). 상사는 모니터링 과정에서 구성원들의 부정적인 행동을 수집할 수 있는데, 심리적 특권의식이 높은 구성원이 경쟁적 우위를 유지하기 위해 하는 부정적 행 동의 정보도 수집할 수 있다. 따라서 상사가 지속적으로 모니터링 하는 경우에는 조직구성 원들은 심리적 특권의식이 높은 동료의 부정 적 행동을 상사가 교정하거나 피드백 해줄 수 있다고 여길 것이다. 따라서 상사 모니터링은 지식제공자의 손실회피 지식은폐 동기를 감소 시켜서 궁극적으로 지식은폐 행동 수준을 낮 출 수 있을 것이다.

셋째, 지식요청 동료의 심리적 특권의식에 대한 지식제공자의 인식이 부정평가 염려 동 기를 통해 지식은폐 행동 수준을 높이는 관계 를 상사 모니터링이 약화시킬 것이다. 상사가 모니터링을 통해 업무 상 문제를 확인하고 업 무 진행사항에 대해 소통하는 행동은 구성원 들에 대한 높은 관심과 지원 행동으로 인식될 수 있다. 자원 보존 이론에 따르면, 자원은 사 회적 지원, 보상, 자율성, 고용 안정 등이며, 자원은 개인, 집단, 상사, 조직에서 얻을 수도 있고 잃을 수도 있다. 그 중 상사의 사회적 지원은 업무몰입 수준을 높이고, 업무에 필요 한 정서적인 자원을 축적하게 한다(Kalshoven \& Boon, 2012). Komaki 등(1986)이 제시한 커뮤 니케이션 모니터링은 상사에게 업무의 세부 내용을 보고하여 문제를 해결할 수 있으므로 상사 모니터링을 상사의 지원으로 간주할 수 있다. 상사가 커뮤니케이션 모니터링을 통해 구성원들의 성과에 대해 논의하고 의견을 주 
고받는 과정은 구성원들이 가진 수행 상 어려 움이나 문제를 확인하는 과정이다(Niehoff \& Moorman, 1993). 따라서 심리적 특권의식이 높 은 동료로부터 받는 공격적 행동이나 부정적 피드백에 대한 내용을 상사에게 보고하여 심 리적 불안을 낮추고 문제 해결의 기회를 가질 수 있다. 따라서 상사 모니터링은 지식 제공 의 결과로 발생할 수 있는 부정적 평가에 대 한 두려움을 감소시켜서 궁극적으로 지식은폐 행동 수준을 낮출 수 있을 것이다.

넷째, 지식요청 동료의 심리적 특권의식에 대한 지식제공자의 인식이 부정적 관계 동기 를 통해 지식은폐 행동 수준을 높이는 관계를 상사 모니터링이 약화시킬 것이다. 사회 교환 이론 관점에서, 조직 구성원들은 자신이 투자 한 노력과 그로 인한 결과가 얼마나 형평한가 를 판단하여 교환을 결정한다(Adams, 1965). 따 라서 불공정한 거래 관계라고 인식하게 되면 거래를 거부하거나 회피한다. 지식을 요청받 은 상황에서도 거래의 실패가 일어날 수 있는 데 심리적 특권의식이 높다고 인식한 동료가 상대적으로 더 많은 자원을 확보하려고 한다 면 지식제공자는 불공정한 거래라고 인식할 것이다. 이러한 불공정함에 대한 인식은 지식 요청자에 대한 불신으로 이어질 수 있다. 상 사가 지속적으로 커뮤니케이션 하게 되면, 업 무 추진 과정에서 겪는 어려움을 상사와 공유 할 수 있기 때문에 불공정성 문제도 해결할 기회가 생긴다. 상사 모니터링의 중요한 역할 중 하나는 구성원들의 성과 기여도를 정확하 게 확인하여 절차 공정성을 높이는 것이다 (Niehoff \& Moorman, 1993). 따라서 동료보다 낮은 기여를 통해 불공정하게 자원을 확보하 려는 구성원의 행동은 상사 모니터링을 통해 통제될 수 있다. 지식제공자는 동료와의 지식
공유가 불공정한 거래관계라고 인식하더라도 상사가 동료를 통제하고 처벌할 것이라 믿기 때문에, 상사 모니터링은 지식제공자의 부정 적 관계 동기를 감소시켜서 궁극적으로 지식 은폐 행동 수준을 낮출 수 있을 것이다. 이러 한 선행연구와 추론을 바탕으로 다음과 같은 가설을 설정하였다.

가설 2-1. 상사 모니터링은 지식요청 동료의 심리적 특권의식과 지식제공자의 지식은폐 행 동 간 관계에서 사적소유 동기의 매개효과를 조절할 것이다. 구체적으로, 상사 모니터링이 높을수록 지식제공자의 사적소유 동기의 매개 효과는 작아질 것이다.

가설 2-2. 상사 모니터링은 지식요청 동료의 심리적 특권의식과 지식제공자의 지식은폐 행 동 간 관계에서 손실회피 동기의 매개효과를 조절할 것이다. 구체적으로, 상사 모니터링이 높을수록 지식제공자의 손실회피 동기의 매개 효과는 작아질 것이다.

가설 2-3. 상사 모니터링은 지식요청 동료의 심리적 특권의식과 지식제공자의 지식은폐 행 동 간 관계에서 부정평가 염려 동기의 매개효 과를 조절할 것이다. 구체적으로, 상사 모니터 링이 높을수록 지식제공자의 부정평가 염려 동기의 매개효과는 작아질 것이다.

가설 2-4. 상사 모니터링은 지식요청 동료의 심리적 특권의식과 지식제공자의 지식은폐 행 동 간 관계에서 부정적 관계 동기의 매개효과 를 조절할 것이다. 구체적으로, 상사 모니터링 이 높을수록 지식제공자의 부정적 관계 동기 의 매개효과는 작아질 것이다.

이상의 가설을 종합하여 연구모형으로 나타 내면 Figure 1과 같다. 


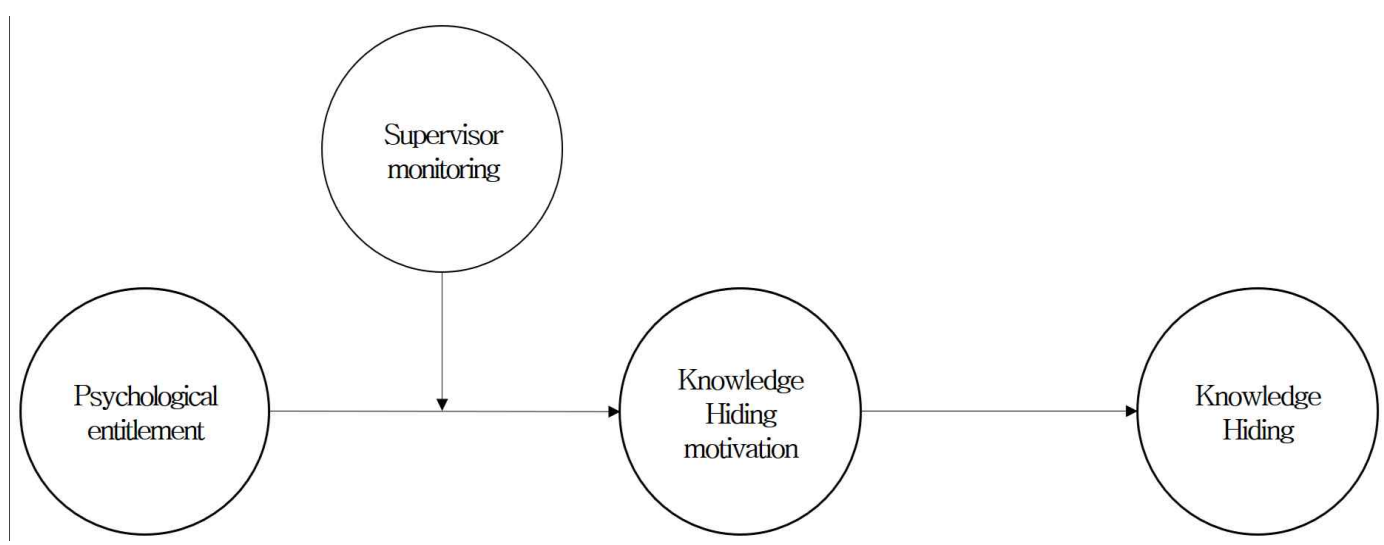

Figure 1. Research model

\section{방 법}

\section{조사대상 및 자료수집 절차}

국내 기업의 다양한 직종에서 근무하고 있 는 구성원들을 대상으로 설문조사를 실시해서 자료를 수집하였다. 설문지는 온라인 설문 조 사 기관을 통해 배포하였으며, 400 명의 응답 을 수집하였다. 현재 소속된 팀/부서가 3 명 이 상이고 구성원이 20 명 이상인 조직에 속한 사 람들만 설문에 참여하도록 제한하였다. 소속 인원을 제한한 것은 소속된 팀과 조직 구성원 이 적을수록 직무의 상호의존성이 낮아 지식 은폐가 빈번하게 일어나지 않기 때문이다. 자 료 수집을 위해 조사대상자들에게 "귀하는 함 께 일을 하는 과정에서 지식을 요청받았던 경 험이 있습니까?”를 물어서 지식은폐 경험 여 부를 먼저 확인하였다. 여기서 지식은 업무에 대한 정보나 업무 처리 방법, 업무 아이디어, 업무 노하우 등을 의미한다고 설명하였다. 이 후 "동료의 지식전달 요청에도 전달하지 않았 던 상황을 떠올려 아래의 문항에 응답해주십 시오."라는 지시문을 통해 지식을 요청한 동
료에게 지식을 은폐한 상황을 떠올리도록 하 였다.

조사대상자의 인구통계학적 특성을 살펴보 면, 전체 400명의 대상자 중에 여성 50\%(200 명), 남성 $50 \%$ (200명)이었고, 연령의 평균은 39 세였다. 교육 수준은 고졸 이하 27명(6.8\%), 전 문대졸 65 명(16.3\%), 대졸 254명(63.5\%), 대학원 졸 54명(13.4\%)이었으며, 연령은 20대 39명 (9.8\%), 30대 156명(41.8\%), 40대 167명(39\%) 50 대 38 명 $(9.4 \%)$ 이었다. 직무는 일반 사무 및 관리 128 명(32\%), 전략/기획 30명(7.5\%), 영업/ 마케팅 24명(6\%), 생산/기술 60명(15\%), 연구/ 개발 54 명(13.5\%), 서비스 70 명(17.5\%), 기타 34 명(8.5\%)이었다. 직급은 사원급 143 명(35.8\%), 대리/선임급 121 명(30.2\%), 과장/책임급 80 명 (20\%), 차장급 46명(11.5\%), 부장급 이상 10 명 (2.5\%)이었다. 직종은 제조 111 명 $(27.8 \%)$, 서비 스 110명(27.5\%), IT 53명(13.2\%), 유통 23명 (5.8\%), 금융 17 명(4.3\%), 기타 86명(21.4\%)이었 다. 현재 근무하고 있는 팀/부서의 인원은 평 균 15 명이었고, 팀 근속년수는 평균 4.2 년이 었다. 
측정도구

\section{지식은폐 동기}

Ko와 $\mathrm{Yoo}(2020)$ 가 개발한 지식제공자의 지 식은폐 동기 17 개 문항을 사용하였다. 지식은 폐 동기는 4개 요인으로 구성되어 있으며, 사 적소유 동기 4 개 문항의 내적일관성 신뢰도 계수(Cronbach's $a$ )는 .90, 손실회피 동기 5개 문항의 내적일관성 신뢰도 계수(Cronbach's a) 는 .94, 부정평가 염려 동기 4 개 문항의 내적 일관성 신뢰도 계수(Cronbach's $a$ )는 .89, 부정 적 관계 동기 4 개 문항의 내적일관성 신뢰도 계수(Cronbach's $a$ )는 .92이다. 문항의 예로 사 적소유 동기는 '내가 가진 지식은 나의 자산 이라고 생각하기 때문이다.', 손실회피 동기는 '나의 아이디어를 가로챌 수 있기 때문이다.', 부정평가 염려 동기는 '전달한 지식에 대한 부정적인 반응이 두려웠기 때문이다.', 부정적 관계 동기는 '지식요청 동료와 평소 사이가 안 좋기 때문이다.' 등이다. 각 문항에 대해 얼마나 동의하는지를 Likert 5점 척도(1점: 전 혀 그렇지 않다, 5점: 매우 그렇다)를 사용하 여 평정하였다.

\section{지식은폐 행동}

Connelly 등(2012)이 개발한 지식제공자의 지 식은폐 행동 12 개 문항을 사용하였다. 지식은 폐 행동의 내적일관성 신뢰도 계수(Cronbach's a)는 .95이다. 문항의 예는 '내가 그 일을 담당 했지만, 잘 모른다고 대답한다.', '동료가 실제 로 원하는 정보 대신 다른 정보를 전달한다.', '상사의 지시 때문에 지식을 공유할 수 없다 고 말한다.' 등이다. 각 문항에 대해 얼마나 동의하는지를 Likert 7점 척도(1점: 전혀 그렇 지 않다, 7점: 매우 그렇다)를 사용하여 평정
하였다.

\section{지식요청 동료의 심리적 특권의식}

지식요청 동료의 심리적 특권의식은 지식제 공자가 지식요청 동료에 대해 평소에 인식하 고 있는 정도로 측정하였다. 지식요청 동료의 심리적 특권의식에 대한 지식제공자의 인식은 Campbell 등(2004)의 9개 문항을 사용하였다. 지식요청 동료의 심리적 특권의식의 내적일관 성 신뢰도 계수(Cronbach's a)는 .95이다. 문항 의 예는 지식요청 동료는 '다른 사람들보다 더 나은 대접을 받아야 한다고 생각한다.', '모 든 일은 자신의 뜻대로 되어야만 한다고 생각 한다.', '특별한 대우를 받을 만한 자격이 있다 고 생각한다.' 등이다. 각 문항에 대해 얼마나 동의하는지를 Likert 7점 척도(1점: 전혀 그렇 지 않다, 7점: 매우 그렇다)를 사용하여 평정 하였다.

\section{상사 모니터링}

Niehoff와 Moorman(1993)의 13개 문항 중 상 사의 커뮤니케이션 모니터링 5 개 문항을 사용 하였다. Niehoff와 Moorman(1993)이 제시한 상 사 모니터링의 세 가지 요인은 직접 관찰에 의한 모니터링, 커뮤니케이션 모니터링, 공식 적 회의를 통한 모니터링이다. 직접 관찰에 의한 모니터링 5 개 문항은 '나의 상사는 일하 는 업무 공간을 순찰한다.', '나의 상사는 일하 고 있을 때 나를 지켜본다.' 등으로 상사가 직 접 관찰을 하는지 여부를 묻는 문항으로 구성 되어 있다. 상사의 관찰 행동은 구성원과 직 접 상호작용을 하기 보다는 단순히 일하는 모 습을 지켜보는 빈도를 측정하는 문항이기 때 문에, 직접적으로 공정성에 대한 인식을 높이 는 행동이라고 보기 어렵다. 따라서 직접 관 
찰에 의한 모니터링은 오히려 지식공유 행동 을 저해할 가능성이 있기 때문에 본 연구에서 제외하였다. 또한 공식적 회의를 통한 모니터 링 3 개 문항은 단순하게 회의 빈도만을 측정 하기 때문에 모니터링을 위한 행동 의도가 포 함되어 있지 않아서 본 연구에서 제외하였다. 본 연구에서 사용한 상사 커뮤니케이션 모니 터링의 내적일관성 신뢰도 계수(Cronbach's a) 는 .90 이다. 문항의 예는 '나의 상사는 세부 업무내용에 대해 파악하기 위해 개인적으로 대화한다.', '나의 상사는 업무 진행 상황에 대 해 개인적으로 대화한다.', '나의 상사는 업무 상 문제점 파악을 위해 개인적으로 대화한다.' 등이다. 각 문항에 대해 Likert 5점 척도(1점: 전혀 하지 않는다, 5점: 매우 자주한다)를 사 용하여 행동 빈도를 측정하였다.

\section{분석 방법}

분석을 위해 SPSS 22.0 프로그램과 Mplus 7.0 프로그램을 사용하였다. 첫째, 연구에 사 용된 각 변인들의 신뢰도 계수(Cronbach's $a$ )를 확인하기 위해, SPSS 22.0 을 사용하여 신뢰도 분석을 실시하였다. 둘째, 변인을 측정하는 도 구가 실제로 구성개념을 명확하게 측정하고 있는지를 파악하기 위해, Mplus 7.0을 사용하 여 탐색적 요인분석과 확인적 요인분석을 응 답자 400 명을 대상으로 실시하였다. 탐색적 요인분석은 지식은폐 동기 4 요인 모형이 1,2 , 3 요인으로 구성된 모형과 비교하여 가장 적합 한 모형인지 알아보기 위해 실시하였다. 확인 적 요인분석은 지식요청 동료의 심리적 특권 의식, 지식제공자의 지식은폐 동기, 지식제공 자의 지식은폐 행동, 상사 모니터링으로 구성 된 측정모형이 적합한지를 알아보기 위해 실
시하였다. 셋째, 변인들 간의 관계를 알아보기 위해 SPSS 22.0을 사용하여 기술통계 분석과 상관분석을 실시하였다. 넷째, Mplus 7.0을 사 용하여 부트스트랩핑 분석(bootstrapping analysis) 을 통해 다중매개효과의 유의성을 확인하였다. 다섯째, Mplus 7.0을 사용하여 상사 모니터링 의 조절된 매개효과를 검증하였다. 조절된 매 개효과는 Cheung과 $\mathrm{Lau}(2017)$ 의 잠재조절구조 방정식(LMS: latent moderated structural equation) 모형을 이용하여 통계적 유의성을 검증하였다. 잠재조절구조방정식을 사용하는 분석 방법 은 일반적인 적합도가 제시되지 않고 로그우 도 값과 정보준거 값(AIC, $\mathrm{BIC}, \mathrm{SABIC}$ 만 제시 된다. 일반적인 적합도는 정규이론에 입각하 고 있지만 LMS는 그렇지 않기 때문이다(Lee, 2018). 이러한 특징에 따라, 연구자들은 잠재 변인을 이용한 조절된 매개효과를 분석하는 경우에는 2단계 방법을 이용할 것을 제안하였 다(Sardeshmukh \& Vandenberg, 2017). 본 연구도 연구자들의 제안에 따라 분석을 실시하였다. 첫째, 잠재상호작용항을 제외한 모형(기저모 형)을 추정하였다. 모형추정결과, 적합도가 양 호하고 요인적재치들이 유의하면 관측변인들 이 해당 요인을 잘 측정한다고 보았다. 기저 모형추정을 통한 모형의 적합도는 $\mathrm{CFI}, \mathrm{TLI}$, RMSEA, SRMR 지수로 평가하였다. 둘째, 잠재 상호작용항이 포함된 조절된 매개모형을 분석 하였다. 이때 기저모형과 잠재상호작용항이 포함된 조절된 매개모형의 $\mathrm{AIC}$ 값을 비교하여 어느 모형의 AIC 값이 상대적으로 더 낮은지 를 확인하였다. AIC 값이 상대적으로 더 낮은 모형이 더 우수한 모형이므로, 이를 통해 조 절된 매개모형의 적합도가 더 우수한지 확인 하였다. 그리고 잠재조절변인의 여러 수준에 서의 조건부 매개효과들을 비교하여 이들 효 
과들의 유의성 여부를 확인하였다.

Cheung과 $\mathrm{Lau}(2017)$ 는 이러한 2단계 분석에 추가하여 조절효과를 탐색하는 3 단계를 분석 하는 것을 권장한다. 본 연구에서도 연구자들 의 제안에 따라 조절효과를 추가적으로 검증 하였다. 또한 잠재조절구조방정식에 의한 조 절된 매개모형분석은 분석결과에서 매개효과 의 통계적 유의성을 제시하지 않기 때문에 매 개효과도 추가로 검증하였다. 매개모형의 분 석결과를 가설검증의 우선적 판정기준으로 상 정한다면, 조절된 매개모형 분석결과의 재검 증적 성격을 지닐 수 있기 때문이다(Oh, 2020).

\section{결 과}

\section{측정변인들의 기술통계치와 상호상관}

본 연구에서 측정한 주요변인인 지식요청 동료의 심리적 특권의식, 지식제공자의 지식 은폐 동기(사적소유, 손실회피, 부정평가 염려, 부정적 관계), 지식제공자의 지식은폐 행동,
상사 모니터링 간 관계를 Table 1 에 제시하였 다. 주요 변인들의 상관분석 결과를 제시하면 다음과 같다.

사적소유 지식은폐 동기 $(r=.63, p<.001)$, 손 실회피 지식은폐 동기 $(r=.63, p<.001)$, 부정평 가 염려 지식은폐 동기 $(r=55, p<.001)$, 부정적 관계 지식은폐 동기 $(r=.49, p<.001)$ 는 모두 지 식은폐 행동과 유의한 정적인 상관관계를 보 였다. 지식요청 동료의 심리적 특권의식은 지 식제공자의 사적소유 지식은폐 동기 $(r=.35, p<$ $.001)$, 손실회피 지식은폐 동기 $(r=.38, p<.001)$ 부정평가 염려 지식은폐 동기 $(r=23, p<.001)$ 부정적 관계 지식은폐 동기( $r=.31, p<.001)$, 지 식은폐 행동 $(r=.44, p<.001)$ 과 유의한 정적인 상관관계를 나타냈다. 상사 모니터링은 사적 소유 지식은폐 동기 $(r=-.25, p<.001)$, 손실회피 지식은폐 동기 $(r=-.24, p<.001)$, 부정평가 염려 지식은폐 동기 $(r=-29, p<.001)$, 부정적 관계 지 식은폐 동기 $(r=-.23, p<.001)$, 지식은폐 행동 $(r=-31, p<.001)$ 과 모두 유의한 부적인 상관관 계를 보였다.

Table 1. Mean, standard deviation, intercorrelations, and reliability for variables

\begin{tabular}{lcccccccccc}
\hline & Variables & Mean & SD & 1 & 2 & 3 & 4 & 5 & 6 & 7 \\
\hline 1 & Personal Ownership & 2.65 & .97 & $(.90)$ & & & & & \\
\hline 2 & Fear of Loss & 2.46 & .99 & $.79^{* * *}$ & $(.94)$ & & & & \\
\hline 3 & Concern for Negative Evaluation & 2.49 & .92 & $.55^{* * *}$ & $.58^{* * *}$ & $(.89)$ & & & \\
\hline 4 & Negative Relation & 2.57 & 1.05 & $.58^{* * *}$ & $.53^{* * *}$ & $.43^{* * *}$ & $(.92)$ & & \\
\hline 5 & Knowledge Hiding & 2.91 & 1.24 & $.63^{* * *}$ & $.63^{* * *}$ & $.55^{* * *}$ & $.49^{* * *}$ & $(.95)$ & \\
\hline 6 & Psychological Entitlement & 3.82 & 1.25 & $.35^{* * *}$ & $.38^{* * *}$ & $.23^{* * *}$ & $.31^{* * *}$ & $.44^{* * *}$ & $(.95)$ & \\
\hline 7 & Supervisor Monitoring & 3.37 & .73 & $-.25^{* * *}$ & $-.24^{* * *}$ & $-.29^{* * *}$ & $-.23^{* * *}$ & $-.31^{* * *}$ & $.15^{* *}$ & $(.90)$ \\
\hline
\end{tabular}

Note 1. Reliability(Cronbach's alpha) is along the diagonal in parenthesis.

$N=400,{ }^{* *} p<.01, \quad{ }^{* * *} p<.001$ 


\section{측정모형의 적합도 검증}

지식은폐 동기 4요인에 대한 적합도 검증을 위해 Mplus 7.0 프로그램으로 탐색적 요인분석 을 실시하였다. 모형의 추정 방법은 최대우도 법(maximum likelihood; ML), 요인 구조의 회전 은 Geomin 사각 회전을 이용하였다. 지식요청 동료의 심리적 특권의식, 지식제공자의 지식 은폐 동기, 지식은폐 행동, 상사 모니터링으로 구성된 측정모형에 대한 적합도를 알아보기 위해 확인적 요인분석을 실시하였다. 모형의 적합도를 평가하기 위한 적합도 지수로 TLI, CFI, RMSEA, SRMR을 사용하였다. RMSEA는 .05 이하면 좋은 적합도, .08 이하면 양호한 적합 도, .10 이하는 보통 적합도, .10초과는 나쁜 적 합도로 간주한다(Hu \& Bentler, 1999). CFI와 TLI는 .95 이상이면 좋은 모형, .90 .94이면 양 호한 수준, SRMR은 .08보다 낮을 때 모형 적 합도를 좋은 수준으로 해석한다(Hu \& Bentler, 1999).

지식은폐 동기 4 요인의 적합도를 분석한 결 과, Table 2 에서 보듯이 모든 적합도 지수에서
1요인, 2요인, 3요인 모형에 비해 지식은폐 동 기 4 요인이 가장 적합한 모형이라는 것을 알 수 있다.

지식요청 동료의 심리적 특권의식, 지식제 공자의 지식은폐 동기, 지식은폐 행동, 상사 모니터링으로 구성된 측정모형에 대한 적합도 를 분석한 결과, $X^{2}=2474.051(d f=839, p<.001)$ 로 나타났으나, $X^{2}$ 값은 표본 크기에 민감하므 로(Kim, 2016), SRMR, TLI, CFI, RMSEA를 기준 으로 모형의 적합도를 확인하였다. 분석 결과, $\mathrm{CFI}=.895, \mathrm{TLI}=.887, \mathrm{RMSEA}=.070, \mathrm{SRMR}=.055$ 로 나타났다.

측정모형의 적합도를 높이기 위해 Connelly 등(2012)이 제안한 지식은폐 3요인에 근거하여 얼버무리기, 합리화하기, 바보같이 굴기 요인 으로 문항 묶음을 실시한 뒤 재분석하였다 (Model 1). Table 3에서 보듯이, Model 1은 $X^{2}=$ $1188.925(\mathrm{~d} f=506, p<.001), \mathrm{CFI}=.942, \mathrm{TLI}=.936$, $\mathrm{RMSEA}=.058, \mathrm{SRMR}=.050$ 으로 모든 지수들이 모형 적합도 기준치에 부합하여 측정모형이 적합하다고 판단하였다. Model 2는 경쟁모형으 로 지식은폐 동기를 1 개 요인으로 설정하고

Table 2. Fit Indices for knowledge hiding motivation scale

\begin{tabular}{ccccccc}
\hline Model & $X^{2}$ & $d f$ & SRMR & CFI & TLI & RMSEA \\
\hline 4 factor & 193.157 & 74 & .016 & .980 & .963 & .063 \\
\hline 3 factor & 403.165 & 133 & .029 & .946 & .917 & .095 \\
\hline 2 factor & 922.685 & 103 & .070 & .860 & .815 & .141 \\
\hline 1 factor & 1957.316 & 119 & .108 & .686 & .642 & .197 \\
\hline
\end{tabular}

Table 3. Fit Indices for two different measurement models

\begin{tabular}{ccccccc}
\hline Model & $X^{2}$ & $d f$ & SRMR & CFI & TLI & RMSEA \\
\hline Model 1 & 1188.925 & 506 & .050 & .942 & .936 & .058 \\
\hline Model 2 & 2786.050 & 521 & .070 & .807 & .792 & .104 \\
\hline
\end{tabular}


모형 적합도를 확인해 보았다. 주요 지수들이 모형 적합도 기준치를 충족하지 못하였고 지 식은폐 동기를 4개 요인으로 측정한 Model 1 보다 모든 지수에서 낮은 적합도를 보였다.

\section{지식은폐 동기의 매개효과}

Mplus 7.0을 사용하여 부트스트랩핑 분석 (Bootstrapping analysis)을 통해 다중매개효과의 유의성을 확인하였다. 다중매개모형 분석결과 는 Table 4와 같다. 지식요청 동료의 심리적 특권의식과 지식제공자의 지식은폐 행동 간 관계에서 지식제공자의 지식은폐 동기 총 매 개효과를 검증한 결과, 전체 매개효과 크기는 .371 로 95\% 신뢰구간[.259, .493]에 0이 존재하 지 않아 유의하였다. 지식은폐 네 가지 동기 별로 매개효과를 검증한 결과, 사적소유 동기 는 매개효과 크기가 .140으로 $95 \%$ 신뢰구간 $[.071, .236]$ 에 0 이 포함되지 않아 매개효과가
유의한 것으로 나타났다. 손실회피 동기 역시 매개효과 크기가 .128로 $95 \%$ 신뢰구간[.058, .222]에 0이 포함되지 않아 매개효과가 유의한 것으로 나타났다. 부정평가 염려 동기의 매개 효과 크기도 .072로 $95 \%$ 의 신뢰구간[.031, .133 에 0 이 포함되지 않아 매개효과가 유의한 것으로 나타났다. 부정적 관계 동기는 매개효 과 크기가 .031로 95\%의 신뢰구간[.001, .073] 에 0 이 포함되지는 않았으나 매개효과가 유의 하지 않았다. 따라서 가설 1-1, 1-2, 1-3은 지지 되었지만 1-4는 기각되었다.

지식은폐 네 가지 동기가 지식요청 동료의 심리적 특권의식과 지식제공자의 지식은폐 행 동 간 관계를 매개하는 모형에서 각 경로의 비표준화 계수와 표준화 계수를 Figure 2에 제 시하였다. Figure 2에서 보듯이, 부정적 관계 동기에서 지식은폐 행동으로 가는 경로계수를 제외하고 모든 경로계수가 .001 수준에서 유 의하였다.

Table 4. Mediation effects of knowledge hiding motivations between psychological entitlement and knowledge hiding

\begin{tabular}{|c|c|c|c|c|c|}
\hline Path & Effect & $S E$ & $t$ & BootLLCI & BootULCI \\
\hline Total mediation effect & .371 & .060 & $6.200^{* * *}$ & .259 & .493 \\
\hline $\begin{array}{c}\text { Psychological entitlement } \rightarrow \\
\text { Personal ownership } \rightarrow \text { Knowledge hiding }\end{array}$ & .140 & .041 & $3.387^{* *}$ & .071 & .236 \\
\hline $\begin{array}{c}\text { Psychological entitlement } \rightarrow \\
\text { Fear of loss } \rightarrow \text { Knowledge hiding }\end{array}$ & .128 & .041 & $3.098^{* *}$ & .058 & .222 \\
\hline $\begin{array}{c}\text { Psychological entitlement } \rightarrow \\
\text { Concern for negative evaluation } \rightarrow \text { Knowledge hiding }\end{array}$ & .072 & .025 & $2.810^{* *}$ & .031 & .133 \\
\hline $\begin{array}{l}\text { Psychological entitlement } \rightarrow \\
\text { Negative relation } \rightarrow \text { Knowledge hiding }\end{array}$ & .031 & .018 & 1.756 & .001 & .073 \\
\hline
\end{tabular}

Note. $\mathrm{CI}=$ Confidence Interval, BootLLCI $=$ Boot Lower Limit within $95 \%$ confidence interval of indirect effect, BootULCI $=$ Boot Higher Limit within $95 \%$ confidence interval of indirect effect 


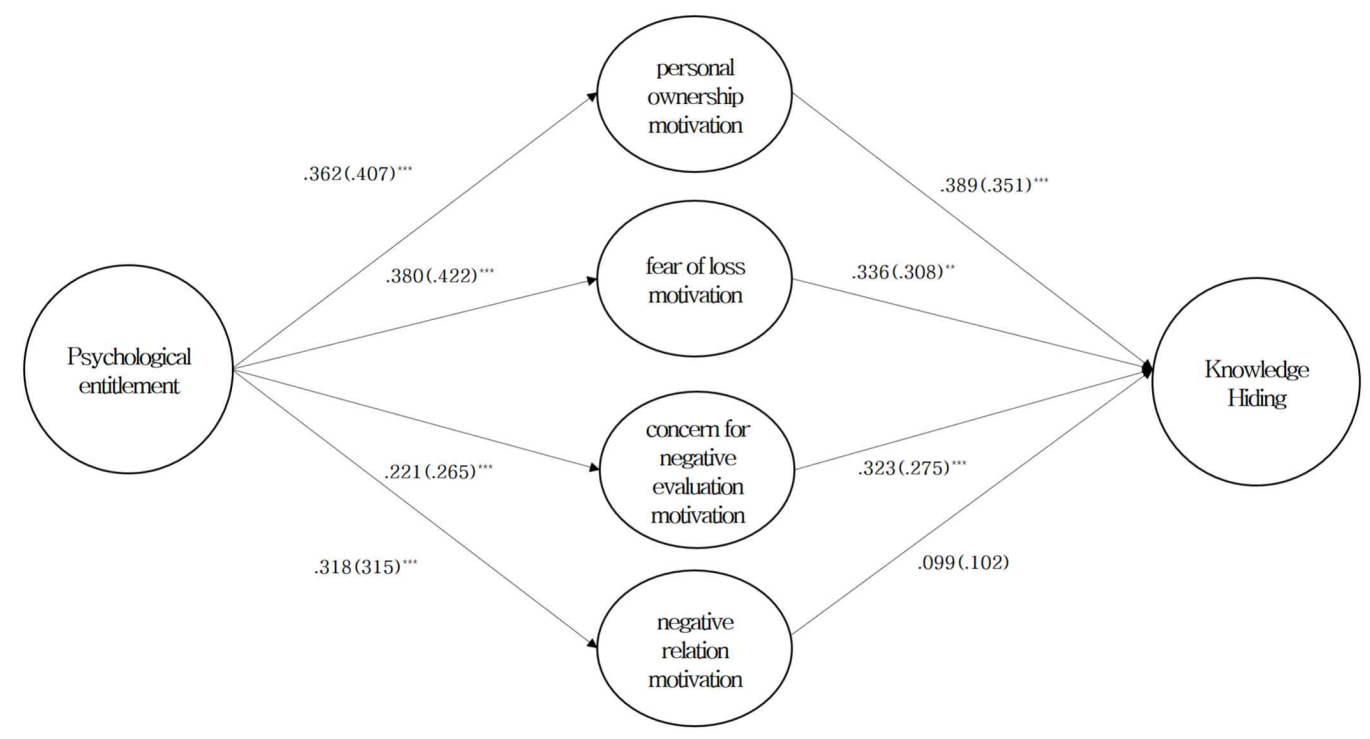

${ }^{* * *} p<.001$

Figure 2. Multiple mediation model of knowledge hiding motivation between psychological entitlement and knowledge hiding

Note. The value in parenthesis means the standardized coefficient.

\section{상사 모니터링의 조절된 매개효과}

심리적 특권의식, 사적소유 동기, 지식은 폐 간 관계에서 상사 모니터링의 조절된 매 개효과

지식제공자의 지식은폐 동기 중 사적소유 동기가 지식요청 동료의 심리적 특권의식과 지식제공자의 지식은폐 행동 간 관계를 매개 하는 효과를 상사 모니터링이 조절하는지 검 증하였다. 이를 위해 Cheung과 Lau(2017)의 조 절된 매개효과 검증에 따라 매개모형과 조절 모형의 유의성을 검증하였다. 지식요청 동료 의 심리적 특권의식과 지식제공자의 지식은폐 행동 간 관계에서 지식제공자의 사적소유 지 식은폐 동기 매개효과의 크기는 Table 4에 제 시한 것처럼 .140 으로 $95 \%$ 신뢰구간..071, .2361 에서 0 의 값이 존재하지 않아 매개효과가
유의하였다. 다음으로 상사 모니터링이 지식 요청 동료의 심리적 특권의식과 지식제공자의 사적소유 동기 간 관계를 조절하는지를 검증 하였다. 그 결과, Table 5에서 보듯이 지식요청 동료의 심리적 특권의식과 상사 모니터링의 상호작용이 지식제공자의 사적소유 동기에 미 치는 영향은 $-.123(p<.05)$ 으로 유의하였다.

다음으로 잠재 상호작용항이 포함되지 않 은 모형(기저모형)의 적합도를 추정하였는데, 모형 적합도는 $X^{2}=524.802(d f=184, p<.001)$, $\mathrm{CFI}=.949, \mathrm{TLI}=.942, \mathrm{RMSEA}=.068, \mathrm{SRMR}=.052$ 로 좋은 적합도를 보였으며, 요인 적재치는 모두 유의하였다. 기저모형과 조절된 매개모 형(잠재 상호작용항이 포함된 모형)의 AIC지수 들을 비교하여, 어느 모형의 $\mathrm{AIC}$ 값이 상대적 으로 더 낮은지 확인하여 모형 적합도를 비교 하였다. 잠재 상호작용항이 포함되지 않은 기 
Table 5. Moderating effect of supervisor monitoring between psychological entitlement and personal ownership motivation

\begin{tabular}{|c|c|c|c|c|}
\hline IV & DV & $B$ & $S E$ & $t$ \\
\hline Psychological entitlement & \multirow{3}{*}{$\begin{array}{l}\text { Personalownership } \\
\text { motivation }\end{array}$} & .392 & .048 & $8.111^{* * *}$ \\
\hline Supervisor monitoring & & -.459 & .067 & $-6.880^{* * *}$ \\
\hline Psychological entitlement x Supervisor monitoring & & -.123 & .057 & $-2.159^{*}$ \\
\hline
\end{tabular}

저모형의 $\mathrm{AIC}(20951.051)$ 와 조절된 매개모형의 $\mathrm{AIC}(20947.934)$ 를 비교한 결과, $\triangle \mathrm{AIC}=3.117$ 로 조절된 매개모형이 더 양호한 것으로 나타났 다. 조절된 매개효과 검증을 위한 모든 조건 이 충족되어서 상사 모니터링의 조절된 매개
효과가 통계적으로 유의한지 검증하였다.

분석 결과, Table 6에서 보듯이 상사 모니터 링의 조절된 매개효과 계수가 $-.107(p<.05)$ 로 조절된 매개효과가 유의한 것으로 나타났다. 상사 모니터링의 조절된 매개효과는 전 구간

Table 6 . The moderated mediation effect of supervisor monitoring by personal ownership

\begin{tabular}{|c|c|c|c|c|c|}
\hline Path & \multicolumn{2}{|c|}{$B$} & $S E$ & \multicolumn{2}{|c|}{$t$} \\
\hline Psychological entitlement $\rightarrow$ Personal ownership & \multicolumn{2}{|c|}{.394} & .048 & \multicolumn{2}{|c|}{$8.150^{* * *}$} \\
\hline Supervisor monitoring $\rightarrow$ Personal ownership & \multicolumn{2}{|c|}{-.488} & .067 & \multicolumn{2}{|c|}{$-7.289^{* * *}$} \\
\hline $\begin{array}{l}\text { Psychological entitlement x Supervisor monitoring } \\
\qquad \rightarrow \text { Personal ownership }\end{array}$ & \multicolumn{2}{|c|}{-.135} & .058 & \multicolumn{2}{|c|}{$-2.325^{*}$} \\
\hline Psychological entitlement $\rightarrow$ Knowledge hiding & \multicolumn{2}{|c|}{.245} & .052 & \multicolumn{2}{|c|}{$4.683^{* * *}$} \\
\hline Personal ownership $\rightarrow$ Knowledge hiding & \multicolumn{2}{|c|}{.798} & .070 & \multicolumn{2}{|c|}{$11.377^{* * *}$} \\
\hline \multirow{2}{*}{ Moderated mediating effect of supervisor monitoring } & \multirow[b]{2}{*}{$B$} & \multirow[b]{2}{*}{$S E$} & \multirow[b]{2}{*}{$t$} & \multicolumn{2}{|c|}{$95 \% \mathrm{CI}$} \\
\hline & & & & LLCI & ULCI \\
\hline$-2 \mathrm{SD}$ & .465 & .086 & $5.379^{* * * *}$ & .295 & .634 \\
\hline$-1 \mathrm{SD}$ & .390 & .060 & $6.538^{* * * *}$ & .273 & .507 \\
\hline Mean & .315 & .043 & $7.255^{* * *}$ & .230 & .400 \\
\hline$+1 \mathrm{SD}$ & .240 & .050 & $4.852^{* * *}$ & .143 & .337 \\
\hline$+2 \mathrm{SD}$ & .165 & .072 & $2.283^{*}$ & .023 & .307 \\
\hline Moderated mediation index & -.107 & .049 & $-2.210^{*}$ & -.203 & -.012 \\
\hline
\end{tabular}

${ }^{*} p<.05, \quad{ }^{* * * *} p<.001$

Note. $\mathrm{CI}=$ Confidence Interval; $\mathrm{LLCI}=$ Lower Limit within $95 \%$ confidence interval of indirect effect, ULCI $=$ Higher Limit within $95 \%$ confidence interval of indirect effect 


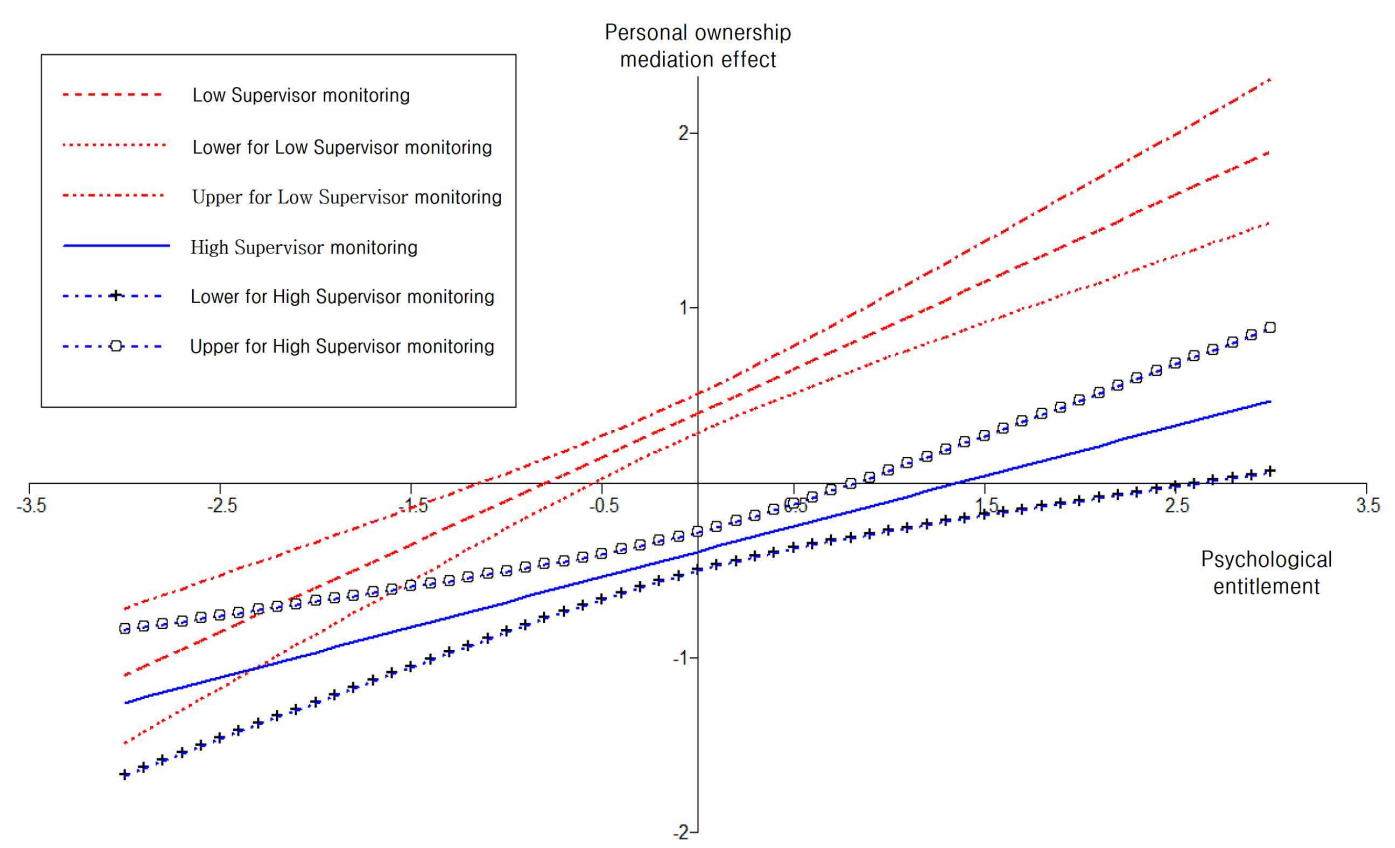

Figure 3. The moderated mediation effect of supervisor monitoring by personal ownership Note. Low Supervisor monitoring $=\mathrm{M}-1 \mathrm{SD}$, Lower for Low Supervisor monitoring $=$ Lower Limit for $\mathrm{M}-1 \mathrm{SD}$,

Upper for low Supervisor monitoring $=$ Higher Limit for $\mathrm{M}-1 \mathrm{SD}$, High Supervisor monitoring $=\mathrm{M}+1 \mathrm{SD}$,

Lower for High Supervisor monitoring=Lower Limit for $\mathrm{M}+1 \mathrm{SD}$,

Upper for High Supervisor monitoring $=$ Higher Limit for $\mathrm{M}+1 \mathrm{SD}$

$( \pm 2 \mathrm{SD}, \pm 1 \mathrm{SD}, \mathrm{Mean})$ 에서 유의하였다. 이러한 결과가 가설에서 예측한 방향과 일치하는지 알아보기 위해 신뢰밴드(Confidence band) 그 래프를 작성하여 확인하였다. Figure 3에서 보듯이, 상사의 모니터링 수준이 낮을 때(Low Supervisor monitoring, $\mathrm{M}-1 \mathrm{SD}$ 구간)보다 상사 의 모니터링 수준이 높을 때(High Supervisor monitoring, $\mathrm{M}+1 \mathrm{SD})$, 지식제공자의 사적소유 동 기 매개효과 크기가 점차 작아지는 것을 알 수 있다. 따라서 상사 모니터링이 높을수록 지식제공자의 사적소유 동기 매개효과가 작아 질 것이라는 가설 2-1이 지지되었다.
심리적 특권의식, 손실회피 동기, 지식은 폐 간 관계에서 상사 모니터링의 조절된 매 개효과

지식제공자의 지식은폐 동기 중 손실회피 동기가 지식요청 동료의 심리적 특권의식과 지식제공자의 지식은폐 행동 간 관계를 매개 하는 효과를 상사 모니터링이 조절하는지 검 증하였다. Table 4에 제시한 것처럼, 지식요청 동료의 심리적 특권의식과 지식제공자의 지식 은폐 행동 간 관계에서 지식제공자의 손실회 피 동기의 매개효과 크기는 .128 로 $95 \%$ 신뢰 구간 $[.058, .222]$ 에서 0 의 값이 존재하지 않아 매개효과가 유의한 것으로 나타났다. 다음으 로 상사 모니터링이 지식요청 동료의 심리적 
Table 7. Moderating effect of supervisor monitoring between psychological entitlement and fear of loss motivation

\begin{tabular}{|c|c|c|c|c|}
\hline IV & DV & $B$ & $S E$ & $t$ \\
\hline Psychological entitlement & \multirow{3}{*}{$\begin{array}{c}\text { Fear of loss } \\
\text { motivation }\end{array}$} & .413 & .049 & $8.445^{* * *}$ \\
\hline Supervisor monitoring & & -.444 & .063 & $-7.003^{* * *}$ \\
\hline Psychological entitlement $\mathrm{x}$ Supervisor monitoring & & -.171 & .060 & $-2.862^{* *}$ \\
\hline
\end{tabular}

특권의식과 지식제공자의 손실회피 동기 간 관계를 조절하는지를 검증하였다. 그 결과, Table 7에서 보듯이 지식요청 동료의 심리적 특권의식과 상사 모니터링의 상호작용이 지식 제공자의 손실회피 동기에 미치는 영향은 $-.171(p<.01)$ 로 유의하였다.

다음으로 잠재 상호작용항이 포함되지 않
은 모형(기저모형)의 적합도를 추정하였는데, 모형 적합도는 $X^{2}=569.240(d f=204, p<.001)$, $\mathrm{CFI}=.951, \mathrm{TLI}=.944, \mathrm{RMSEA}=.067, \mathrm{SRMR}=.052$ 로 좋은 적합도를 보였으며, 요인 적재치는 모두 유의하였다. 기저모형과 조절된 매개모 형(잠재 상호작용항이 포함된 모형)의 AIC지수 들을 비교하여, 어느 모형의 AIC 값이 상대적

Table 8. The moderated mediation effect of supervisor monitoring by fear of loss

\begin{tabular}{|c|c|c|c|c|c|}
\hline Path & \multicolumn{2}{|c|}{$B$} & $S E$ & \multicolumn{2}{|c|}{$t$} \\
\hline Psychological entitlement $\rightarrow$ Fear of loss & \multicolumn{2}{|c|}{.416} & .049 & \multicolumn{2}{|c|}{$8.503^{* * *}$} \\
\hline Supervisor monitoring $\rightarrow$ Fear of loss & \multicolumn{2}{|c|}{-.463} & .064 & \multicolumn{2}{|c|}{$-7.274^{* * *}$} \\
\hline $\begin{array}{l}\text { Psychological entitlement } \mathrm{x} \text { Supervisor monitoring } \\
\qquad \rightarrow \text { Fear of loss }\end{array}$ & \multicolumn{2}{|c|}{-.178} & .060 & \multicolumn{2}{|c|}{$-2.980^{* *}$} \\
\hline Psychological entitlement $\rightarrow$ Knowledge hiding & \multicolumn{2}{|c|}{.239} & .057 & \multicolumn{2}{|c|}{$4.182^{* * *}$} \\
\hline Fear of loss $\rightarrow$ Knowledge hiding & \multicolumn{2}{|c|}{.763} & .065 & \multicolumn{2}{|c|}{$11.698^{* * *}$} \\
\hline \multirow[b]{2}{*}{ Moderated mediating effect of supervisor monitoring } & \multirow[b]{2}{*}{$B$} & \multirow[b]{2}{*}{$S E$} & \multirow[b]{2}{*}{$t$} & \multicolumn{2}{|c|}{$95 \% \mathrm{CI}$} \\
\hline & & & & LLCI & ULCI \\
\hline$-2 \mathrm{SD}$ & .507 & .084 & $6.047^{* * * *}$ & .343 & .672 \\
\hline$-1 \mathrm{SD}$ & .412 & .058 & $7.057^{* * *}$ & .298 & .572 \\
\hline Mean & .318 & .044 & $7.224^{* * * *}$ & .232 & .404 \\
\hline$+1 \mathrm{SD}$ & .223 & .051 & $4.383^{* * * *}$ & .123 & .323 \\
\hline$+2 \mathrm{SD}$ & .128 & .073 & 1.750 & -.015 & .272 \\
\hline Moderated mediation index & -.136 & .048 & $-2.350^{* *}$ & -.229 & -.042 \\
\hline
\end{tabular}




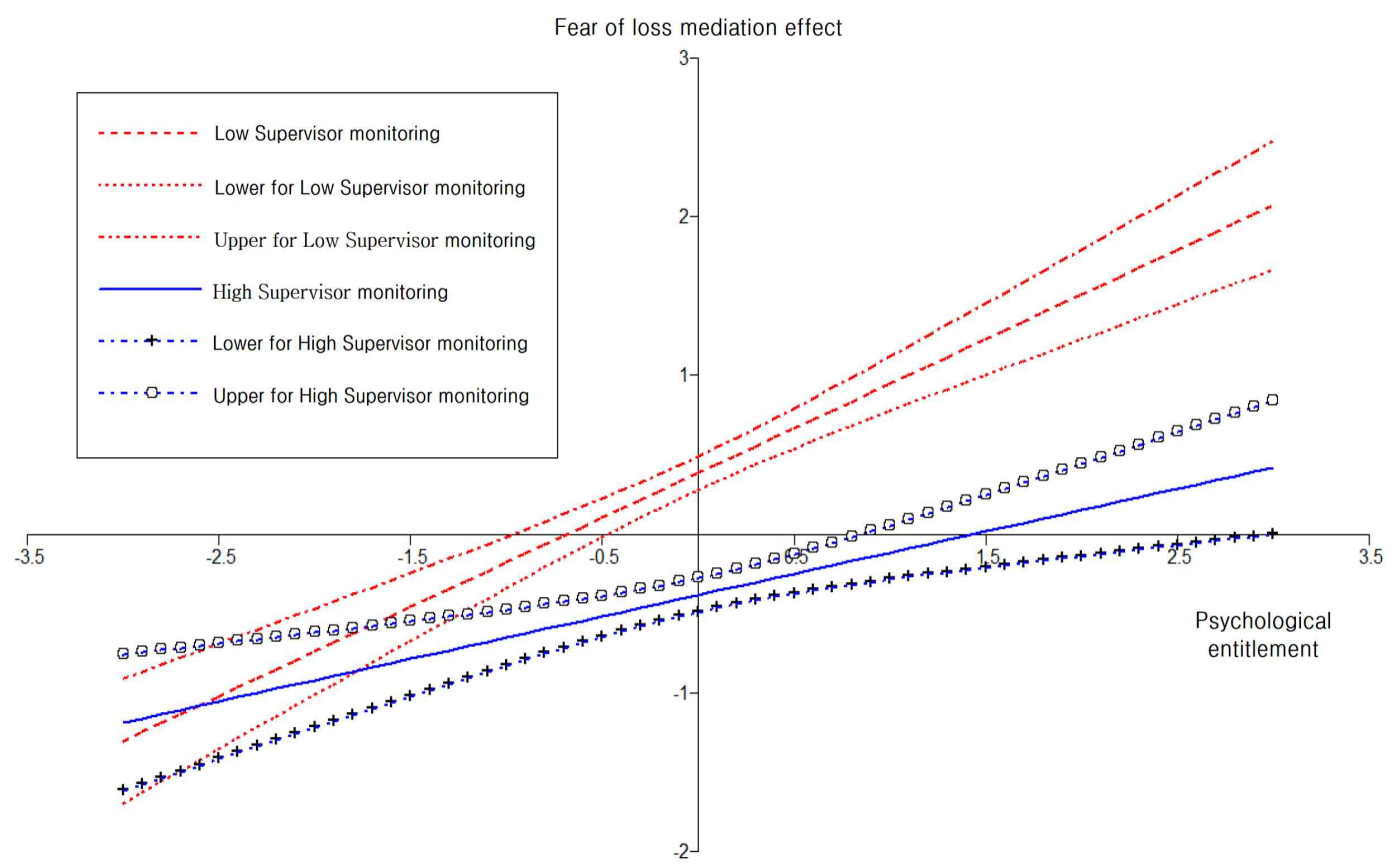

Figure 4. The moderated mediation effect of supervisor monitoring by fear of loss

Note. Low Supervisor monitoring $=\mathrm{M}-1 \mathrm{SD}$, Lower for Low Supervisor monitoring $=$ Lower Limit for $\mathrm{M}-1 \mathrm{SD}$,

Upper for low Supervisor monitoring $=$ Higher Limit for $\mathrm{M}-1 \mathrm{SD}$, High Supervisor monitoring $=\mathrm{M}+1 \mathrm{SD}$,

Lower for High Supervisor monitoring=Lower Limit for M+1SD,

Upper for High Supervisor monitoring $=$ Higher Limit for $\mathrm{M}+1 \mathrm{SD}$

으로 더 낮은지 확인하여 모형적합도를 비교 하였다. 잠재 상호작용항이 포함되지 않은 기 저모형의 $\mathrm{AIC}(21479.302)$ 와 조절된 매개모형의 $\mathrm{AIC}(21471.948)$ 를 비교한 결과, $\triangle \mathrm{AIC}=7.354$ 로 조절된 매개 모형이 더 양호한 것으로 나타났 다. 조절된 매개효과 검증을 위한 모든 조건 이 충족되어서 상사 모니터링의 조절된 매개 효과가 통계적으로 유의한지 검증하였다.

분석 결과, Table 8 에서 보듯이 상사 모니터 링의 조절된 매개효과 계수가 -.136( $p<.01)$ 으로 조절된 매개효과가 유의한 것으로 나타났다. 상사 모니터링의 조절된 매개효과는 $+2 \mathrm{SD}$ 구 간을 제외한 구간 $(-2 \mathrm{SD}, \pm 1 \mathrm{SD}, \mathrm{Mean})$ 에서 유
의한 것으로 나타났다. 이러한 결과가 가설에 서 예측한 방향과 일치하는지 알아보기 위해 신뢰밴드(Confidence band) 그래프를 작성하여 확인하였다. Figure 4에서 보듯이, 상사 모니터 링 수준이 낮을 때(Low Supervisor monitoring, $\mathrm{M}$ $-1 \mathrm{SD}$ 구간)보다 상사의 모니터링 수준이 높 을 때(High Supervisor monitoring, M+1SD), 지식 제공자의 손실회피 동기 매개효과 크기가 점 차 작아지는 것을 알 수 있다. 따라서 상사 모니터링이 높을수록 지식제공자의 손실회피 동기 매개효과가 작아질 것이라는 가설 2-2가 지지되었다. 
심리적 특권의식, 부정평가 염려 동기, 지식 은폐 간 관계에서 상사 모니터링의 조절된 매 개효과

지식제공자의 지식은폐 동기 중 부정평가 염려 동기가 지식요청 동료의 심리적 특권의 식과 지식제공자의 지식은폐 행동 간 관계를 매개하는 효과를 상사 모니터링이 조절하는지 검증하였다. Table 4 에 제시한 것처럼, 지식요 청 동료의 심리적 특권의식과 지식제공자의 지식은폐 행동 간 관계에서 부정평가 염려 동 기의 매개효과 크기는 .072로 $95 \%$ 신뢰구간 $[.031, .133]$ 에서 0 의 값이 존재하지 않아 매개 효과가 유의한 것으로 나타났다. 다음으로, 상 사 모니터링이 지식요청 동료의 심리적 특권 의식과 지식제공자의 부정평가 염려 동기 간 관계를 조절하는지를 검증하였다. 그 결과, 지 식요청 동료의 심리적 특권의식과 상사 모니 터링의 상호작용이 지식제공자의 부정평가 염 려 동기에 미치는 영향은 -.074로 유의하지 않 은 것으로 나타났다. 기저모형을 추정한 결과, 모형 적합도는 $X^{2}=570.739(d f=184, \quad p<.001)$, $\mathrm{CFI}=.941, \mathrm{TLI}=.933, \mathrm{RMSEA}=.072, \mathrm{SRMR}=.055$ 로 양호한 적합도를 보였으며, 요인 적재치는 모두 유의하였다. 잠재 상호작용항이 포함되 지 않은 기저모형의 $\mathrm{AIC}(21009.613)$ 와 조절된 매개모형의 $\mathrm{AIC}(21008.626)$ 를 비교한 결과, $\triangle$ $\mathrm{AIC}=.987$ 으로 조절된 매개 모형이 더 양호한 것으로 나타났다. 하지만 상사 모니터링의 조 절효과가 유의하지 않아서 조절된 매개효과 분석을 위한 조건이 충족되지 않았다. 따라서 상사 모니터링이 높을수록 지식제공자의 부정 평가 염려 동기 매개효과가 작아질 것이라는 가설 2-3은 기각되었다.
심리적 특권의식, 부정적 관계 동기, 지식은 폐 간 관계에서 상사 모니터링의 조절된 매개 효과

지식제공자의 지식은폐 동기 중 부정적 관 계 동기가 지식요청 동료의 심리적 특권의식 과 지식제공자의 지식은폐 행동 간 관계를 매 개하는 효과를 상사 모니터링이 조절하는지 검증하였다. Table 4 에 제시한 것처럼, 지식요 청 동료의 심리적 특권의식과 지식제공자의 지식은폐 행동 간 관계에서 지식제공자의 부 정적 관계 동기 매개효과 크기는 .031로 $95 \%$ 의 신뢰구간 $[.001, .073]$ 에서 0 의 값이 존재하 지 않았지만, 매개효과가 유의하지 않은 것으 로 나타났다. 이러한 결과는 조절된 매개효과 를 검증할 수 없는 조건이기 때문에 상사 모 니터링이 높을수록 지식제공자의 부정적 관계 동기의 매개효과가 작아질 것이라는 가설 2-4 는 기각되었다.

\section{논 의}

본 연구는 지식요청 동료의 심리적 특권의 식에 대한 지식제공자의 인식과 지식제공자의 지식은폐 행동 간 관계에서 지식제공자의 지 식은폐 동기의 매개효과를 알아보았다. 분석 결과, 지식은폐 동기 요인 중 사적소유, 손실 회피, 부정평가 염려 동기가 지식요청 동료의 심리적 특권의식에 대한 지식제공자의 인식과 지식제공자의 지식은폐 행동 간 관계를 매개 하였다. 구체적으로, 심리적 특권의식이 높다 고 인식한 동료가 지식을 요청하면 지식제공 자의 사적소유, 손실회피, 부정평가 염려 동기 가 높아져서 지식은폐 행동 수준이 증가하였 다. 그러나 부정적 관계 지식은폐 동기는 지 
식요청 동료의 심리적 특권의식에 대한 지식 제공자의 인식과 지식제공자의 지식은폐 행동 간 관계를 매개하지 않는 것으로 나타났다.

부정적 관계 동기는 부정적 호혜성에 따라 지식요청 동료와의 관계가 좋지 않거나 과거 에 동료로부터 지식전달을 거부당했을 때 발 생한다. 선행 연구에 따르면, 불공정성을 인식 하는 모든 사람들이 보복적 행동을 하는 것은 아니고, 부정적 호혜성에 대한 믿음이 강한 경우에만 보복적 행동이 나타났다(Gallucci \& Perugini, 2003; Perugin, Gallucci, Presaghi, \& Ercolani, 2003). Irum, Ghosh와 Pandey(2020)는 작업장에서 동료의 무례는 부정적인 정서 사 건으로 인식되어 반생산적 지식은폐 행동이 나타난다는 것을 밝혔다. Akgün, Keskin, Ayar 와 Okunakol(2017)은 소프트웨어 개발 팀에서 지식 전달자와 수신자 간의 의사소통 오류, 적대감, 저항감이 부정적 정서를 높여 지식공 유를 저해한다고 주장하였다. 선행연구에서 다룬 동료에 대한 적대감이나 저항감은 반생 산적 지식은폐 행동과 같은 보복적 행동을 유 발할 만큼 강한 요인이라고 볼 수 있지만, 본 연구에서 다룬 지식요청 동료의 심리적 특권 의식에 대한 인식은 지식제공자에게 부정적 호혜성을 일으킬 만큼 강한 요인으로 인식되 지 않았을 수 있다. 따라서 본 연구에서 이러 한 이유로 부정적 관계 동기의 매개효과가 나 타나지 않았을 것이라고 해석해 볼 수 있다.

또한, 본 연구는 지식요청 동료의 심리적 특권의식에 대한 지식제공자의 인식과 지식제 공자의 지식은폐 행동 간 관계에서 지식제공 자의 지식은폐 동기의 매개효과를 상사 모니 터링이 조절하는지 알아보았다. 그 결과, 지식 요청 동료의 심리적 특권의식이 지식제공자의 사적소유와 손실회피 동기를 통해 지식은폐
행동으로 이어지는 과정을 상사 모니터링이 조절하였다. 구체적으로, 심리적 특권의식이 높다고 인식한 동료가 지식을 요청하면 지식 제공자의 사적소유, 손실회피 동기가 높아져 서 궁극적으로 지식은폐 행동 수준이 높아지 지만, 상사 모니터링은 이러한 관계를 완화시 켰다.

하지만 상사 모니터링은 지식제공자의 부정 평가 염려 동기의 매개효과를 조절하지 않는 것으로 나타났다. 상사 모니터링이 지식제공 자의 부정평가 염려 지식은폐 동기의 매개효 과를 조절하지 않은 결과에 대해 다음과 같이 해석해볼 수 있다. 개인은 향상(promotion)과 예방(prevention)의 자기조절 시스템을 갖고 있 는데, 이 중 예방초점을 지닌 사람은 위험한 상황을 회피하여 부정적인 결과(예, 처벌)를 감소하는 데 목표를 둔다(Higgins, 1997; Kark \& Van Dijk, 2007). 예방초점을 지닌 사람들은 불안한 상황을 회피하고, 상황을 부정적으로 평가하고 판단하려는 경향이 있다(Jones, Briggs \& Smith, 1986; Watson \& Friend, 1969). 부정평 가 염려 동기는 지식 전달 후 받게 되는 부정 적 결과에 대한 두려움 등으로 지식 전달을 거부하려는 동기이므로 예방초점과 관련이 있 다. 부정평가 염려 동기가 높아서 예방에 초 점을 두는 개인은 부정적인 평가를 감소하는 데 목표를 두기 때문에 상사 모니터링이 부정 평가 염려 동기에 영향을 미치지 않을 수 있 다. 따라서 부정평가 염려 동기의 매개효과를 상사 모니터링이 조절하지 않았을 가능성이 있다.

본 연구의 학문적 의의는 다음과 같다. 첫 째, 지금까지 연구는 지식공유, 지식은폐 등 지식을 주고받는 과정에서 개인의 행동을 중 심으로 연구가 진행되어왔고, 지식은폐 동기 
를 주요 변인으로 다룬 실증 연구는 부족하였 다(Connelly et al., 2019). Connelly 등(2012)이 제 안한 지식은폐 행동은 업무와 관련된 정보, 아이디어, 노하우 등의 지식을 다른 사람에게 공유하고 싶지 않을 때, 구성원들이 하는 '시 도와 행동'을 나타낸다. Connelly 등(2012)이 지 식은폐 개념과 척도를 개발한 이후에 진행된 연구에서도 지식은폐의 선행요인이 지식은폐 동기를 거쳐 실제 행동으로 이어지는 과정을 확인한 연구는 거의 수행되지 않았다. 어떠한 동기로 인해 지식은폐 행동이 발생하는지에 따라 지식은폐 행동이 개인 또는 조직에 미치 는 영향과 결과가 달라질 수 있다(Peng, 2013; Connelly et al., 2019). 따라서 본 연구에서 지 식은폐 행동을 유발하는 지식은폐 동기를 네 가지 요인(사적소유, 손실회피, 부정평가 염려, 부정적 관계)으로 구분하여 지식요청 동료의 심리적 특권의식과 지식은폐 행동 간의 관계 를 매개하는 효과를 확인하였다는 데 의의가 있다.

둘째, 지식제공자의 지식은폐 동기를 유발 하는 지식요청 동료의 특성을 확인하였다는 점에 의의가 있다. 기존 연구는 지식은폐 행 동을 일으키는 조직 분위기, 지식제공자의 특 성 등을 다루었지만(Černe et al., 2014; Černe et al., 2017; Cai \& Wen, 2018), 지식을 요청하는 지식요청자의 특성을 다룬 연구는 없었다. Connelly 등(2012)은 지식을 주고받는 과정에서 지식요청자의 특성과 지식요청자와 지식제공 자 간 관계가 지식은폐 행동을 결정하는 가장 중요한 요인이 될 수 있다고 하였다. 그러므 로 앞으로의 연구에서는 지식요청자의 권력 또는 지식요청자의 지식제공자에 대한 대우 등이 지식은폐에 미치는 영향을 다룰 필요가 있다고 주장했다. Tang 등(2015)도 지식은폐는
지식을 요청하는 대상이 존재할 때 발생하는 것이므로 앞으로의 연구에서는 지식요청자의 특성과 지식요청자와 지식제공자 간 관계에 대한 연구가 필요하다고 하였다. 따라서 본 연구에서 지식요청 동료의 특성(심리적 특권 의식)이 지식제공자의 지식은폐에 미치는 영 향을 확인하였다는 데 의의가 있다.

셋째, 지식제공자의 지식은폐 동기를 줄일 수 있는 상사 모니터링의 조절효과를 확인하 였다는 점에 의의가 있다. 기존 연구는 주로 상사의 비인격적 감독, 권한위임 정도, 상사의 지식은폐 행동, 상사와의 과업상호의존성이 지식은폐에 미치는 영향을 다루었다(Khalid et al., 2018; Arain et al., 2020). 그러나 본 연구에 서는 지식을 주고받는 과정에서 공정성을 유 지하도록 하는 상사의 역할로서 상사 모니터 링 효과를 확인하였다. 본 연구에서는 지식요 청자의 심리적 특권의식에 대한 인식이 지식 제공자의 사적소유 동기와 손실회피 동기를 유발해서 지식은폐 행동을 일으키는 과정을 상사 모니터링이 완화한다는 것을 발견하였다.

본 연구의 실무적 시사점은 다음과 같다. 첫째, 지식요청자의 심리적 특권의식이 지식 제공자의 지식은폐 행동을 유발하기 때문에 지식은폐를 예방하기 위해 구성원들의 부정적 특성을 관리할 필요가 있다. 최근 조직은 과 업상호의존성이 높은 팀제로 구성되어 있기 때문에, 함께 일하는 구성원들이 잘 지내고 효과적으로 업무를 처리할 수 있도록 관리하 는 것이 조직성과를 위해 중요하다(Flynn \& Brockner, 2003). 조직에서 상사는 일과 관련된 특정 영역에서 개인의 인식과 행동에 영향을 미칠 수 있지만, 동료는 이보다 더 다양한 영 역에서 개인의 지각과 행동에 영향을 미친다 (Scott \& Bruce, 1994). 본 연구에서는 지식요청 
동료의 심리적 특권의식이 지식제공자의 지식 은폐 동기를 형성하는 중요한 요인이라는 점 을 확인하였다. 따라서 조직은 다면평가 시스 템을 통해 조직에 기여를 덜 하고 구성원들 간 협력을 저해하는 구성원들을 파악하고 관 리할 필요가 있다. 예를 들어, 성과관리 시스 템에 팀 협력에 대한 요인을 동료 진단 문항 으로 추가하여, 자신의 기여와 상관없이 받는 것에만 지나치게 신경을 쓰는 구성원을 파악 할 수 있다. 또한 협력을 저해하는 구성원을 파악해서 적절한 경고와 징계를 한다면, 팀 내 공정성 인식이 높아져서 구성원들의 불만 이 감소하고 지식은폐 행동도 줄어들 것이다.

둘째, 본 연구에서는 상사 모니터링이 지식 제공자의 지식은폐 동기 수준을 낮추고 지식 은폐 행동을 감소시킬 수 있다는 점을 확인하 였다. 따라서 조직은 상사가 평소에 모니터링 을 할 수 있도록 시스템을 마련하고, 상사는 지속적인 커뮤니케이션을 통해 구성원들의 수 행 상황을 모니터링 해야 한다. 상사의 모니 터링은 공정한 성과 평가를 위해 정보를 수집 하는 가장 중요한 과정이다. 특히 커뮤니케이 션 기반의 성과 모니터링은 구성원들이 직접 자신의 업무 상황과 진척도, 일하는 방식을 보고하는 과정이므로, 상사는 구성원과 직접 소통하여 수행 과정에서 겪고 있는 업무적, 대인적 문제점을 파악하고 평가, 코칭, 피드백 을 제공할 수 있다(Stanton, 2000). 상사가 커뮤 니케이션을 통해 구성원들에 대한 성과 모니 터링을 실시한다면, 지식을 은폐하려는 구성 원들의 업무적, 대인적 어려움을 파악하고 해 결할 수 있는 기회를 제공하여 지식은폐를 낮 출 수 있을 것이다.

최근 많은 기업에서는 재택근무, 유연근무 제 등 다양한 공간에서 유동적인 시간으로 근
무할 수 있는 제도를 마련하고 있기 때문에, 상사가 직접 관찰을 통해 구성원들의 성과 정 보를 수집하는 것은 제한적이다. 또한 온라인 으로 지식을 전달하는 경우가 많기 때문에 상 사가 구성원들 간의 지식공유 현황을 파악하 기 어렵다. Zhou(2003)는 상사의 직접적인 관 찰이 성과를 위한 교정 및 피드백을 제공하기 보다는 구성원들로 하여금 지속적으로 통제받 고 있다고 느끼게 해서 구성원들의 자율성을 낮추고 부정적 행동을 유발한다고 하였다. 따 라서 상사가 직접적으로 구성원을 관찰하기보 다는 수시로 상호작용할 수 있는 시스템을 마 련하여 과업 상황을 즉시 확인할 수 있어야 한다. 예를 들어, 온라인 성과 모니터링 시스 템을 통해 상사가 구성원들과 일대일 상호작 용을 수시로 할 수 있으며, 구성원들의 과업 상황을 기록하여 성과 정보를 수집할 수 있다. 이러한 모니터링 시스템은 빈번한 상호작용을 할 수 있게 하여 과업 정보 수집에 효과적일 뿐만 아니라 문제 상황을 즉시 발견하고 대처 할 수 있게 해줄 것이다.

본 연구의 한계점과 향후 지식은폐 관련 연 구를 위한 제안은 다음과 같다. 첫째, 본 연구 에서 사용한 모든 변인은 설문지를 사용하여 자기보고식으로 측정하였기 때문에 동일방법 편의(common method bias)가 발생했을 가능성 이 있다. 그러나 다른 사람의 지식은폐 의도 를 파악하는 것은 어려운 일이며, 지식요청자 의 특성에 대한 지식제공자의 인식이 지식은 폐 의도를 형성하는 것이므로 자기 보고식으 로 측정하는 것이 본 연구에 적합하다고 판단 하였다. Connelly 등(2012)도 구성원들의 지식은 폐 행동을 평가하기 위해 상사 또는 동료에게 질문하여 정확한 평가를 얻어내기 어렵다고 하였으며, 이는 구성원들이 상사나 동료의 부 
정적인 행동을 밝히는 것을 꺼려하기 때문이 라고 설명하였다. Tangirala와 Ramanujam(2008) 은 상사나 동료의 평정은 평가 대상 구성원에 대해 평소에 갖고 있던 인상이나 암묵적 개념 을 반영할 가능성이 크다고 하였다. 단일요인 검증만으로는 공통방법 편향이 발생하지 않는 다고 단정할 수는 없지만, 본 연구에서 단일 요인 검증(Harman's single factor test) 결과, 추 출된 단일요인의 설명 변량은 $21.9 \%$ 로 $50 \%$ 이하의 기준을 충족하였다. 하지만 향후 연구 에서 지식은폐 행동을 타인이 확인할 수 있는 경우에는 타인 평정을 포함해서 자기 평정 결 과와 비교해볼 필요도 있다.

둘째, 본 연구에서 지식제공자의 부정적 관 계 동기는 지식요청 동료의 심리적 특권의식 이 지식은폐에 미치는 영향에서 유의한 매개 효과가 없었다. 부정적 관계 동기는 지식을 요청한 사람에 대해 부정적인 감정을 가지고 있기 때문에 지식을 숨기는 행동을 통해 보복 하려는 동기를 의미한다. 본 연구에서 지식요 청 동료의 심리적 특권의식이 지식제공자의 부정적 관계 동기에 미치는 영향은 유의했지 만, 부정적 관계 동기가 지식은폐 행동에 미 치는 영향은 유의하지 않았다. 본 연구에서 이러한 결과가 나온 한 가지 이유로서 동료의 심리적 특권의식이 유발한 지식제공자의 부정 적 관계 동기가 지식은폐 행동을 할 만큼 강 하지 않았을 가능성을 생각해 볼 수 있다. 따 라서 향후 연구에서 지식요청자에 대한 화, 분노 등의 부정적 정서를 더 강하게 느낄 수 있는 선행 변인의 탐색이 필요하다. 예를 들 어, 지식요청자의 무례, 무시, 따돌림 등은 지 식제공자의 부정적 정서를 강하게 형성하여 지식제공자의 부정적 관계 동기를 높일 수 있 다. 따라서 지식제공자의 부정적 관계 동기를
유발하는 선행 변인을 지식요청 동료의 적대 적 행동을 중심으로 연구해 볼 필요가 있다.

셋째, 본 연구에서는 지식요청자를 동료로 한정해서 연구를 진행하였다. 지식요청 동료 의 심리적 특권의식이 지식제공자의 지식은폐 동기와 지식은폐 행동에 영향을 미친다는 것 을 확인했지만, 향후 연구에서는 지식요청 대 상을 확장해서 연구해볼 필요가 있다. 예를 들어, 지식을 요청하는 상사의 다양한 특성이 부하의 지식은폐 동기와 행동에 미치는 영향 을 알아볼 필요가 있다. 상사는 동료와 다르 게 보상과 처벌을 할 수 있는 권한을 가지고 있기 때문에 동료 특성이 지식은폐에 미치는 영향과는 다른 결과가 나올 가능성이 있을 것 이다.

\section{참고문헌}

Abubakar, A. M., Elrehail, H., Alatailat, M. A., \& Elçi, A. (2019). Knowledge management, decision-making style and organizational performance. Journal of Innovation \& Knowledge, 4(2), 104-114.

https://doi.org/10.1016/j.jik.2017.07.003

Adams, J. S. (1965). Inequity in social exchange. Academic Press, 2, 267-299. https://doi.org/10.1016/S0065-2601(08)60108-2

Akgün, A. E., Keskin, H., Ayar, H., \& Okunakol, Z. (2017). Knowledge sharing barriers in software development teams: A multiple case study in Turkey. Kybernetes, 46(4), 603-620. https://doi.org/10.1108/K-04-2016-0081

Alder, G. S., \& Ambrose, M. L. (2005). An examination of the effect of computerized 
performance monitoring feedback on monitoring fairness, performance, and satisfaction. Organizational Behavior and Human Decision Processes, 97(2), 161-177. https://doi.org/10.1016/j.obhdp.2005.03.003

Anderson, L. M., \& Pearson, C. M. (1999). Tit for tat? the spiraling effect of incivility in the workplace. Academy of Management Review, 24(3), 452-471.

https://doi.org/10.5465/amr.1999.2202131

Antes, A. L., \& Mumford, M. D. (2012). Strategies for leader cognition: viewing the glass "half full" and "half empty". The Leadership Quarterly, 23(3), 425-442. https://doi.org/10.1016/j.leaqua.2011.10.001

Arain, G. A., Bhatti, Z. A., Ashraf, N., \& Fang, Y. H. (2020). Top-down knowledge hiding in organizations: An empirical study of the consequences of supervisor knowledge hiding among local and foreign workers in the middle east. Journal of Business Ethics, 164(3), 611-625.

https://doi.org/10.1007/s10551-018-4056-2

Babcock, P. (2004). Shedding light on knowledge management. HR Magazine, 49(5), 46-51.

https://www.shrm.org/hr-today/news/hr-magazine /pages/0504covstory.aspx

Bavik, Y. L. (2015). Effects of goal interdependence on help-seeking through knowledge sharing and knowledge hiding: the moderating roles of reciprocity beliefs. Master's Thesis, Lingnan University, Hong Kong.

Bogilović, S., Černe, M., \& Škerlavaj, M. (2017). Hiding behind a mask? cultural intelligence, knowledge hiding, and individual and team creativity. European Journal of Work and Organizational Psychology, 26(5), 710-723. https://doi.org/10.1080/1359432X.2017.1337747

Bolino, M. C. (1999). Citizenship and impression management: Good soldiers or good actors? Academy of Management Review, 24(1), 82-98. https://doi.org/10.5465/amr.1999.1580442

Bommer, W. H., Miles, E. W., \& Grover, S. L. (2003). Does one good turn deserve another? coworker influences on employee citizenship. Journal of Organizational Behavior, 24(2), 181-196.

https://doi.org/10.1002/job.187

Cai, F., \& Wen, N. (2018). The influence of Individual goal orientation on innovation behavior from the perspective of knowledge hiding. International Conference on Education, Economics and Management Research, 182(2), 671-676.

https://doi.org/10.2991/iceemr-18.2018.161

Campbell, J. P. (1990). Modeling the performance prediction problem in industrial and organizational psychology. In M. D. Dunnette \& L. M. Hough, Handbook of industrial and organizational psychology. Hove, ES: Consulting Psychologists Press.

Campbell, W. K., Bonacci, A. M., Shelton, J., Exline, J. J., \& Bushman, B. J. (2004). Psychological entitlement: Interpersonal consequences and validation of a self-report measure. Journal of Personality Assessment, 83(1), 29-45.

https://doi.org/10.1207/s15327752jpa8301_04

Černe, M., Hernaus, T., Dysvik, A., \& Škerlavaj, M. (2017). The role of multilevel synergistic 
interplay among team mastery climate, knowledge hiding, and job characteristics in stimulating innovative work behavior. Human Resource Management Journal, 27(2), 281-299. https://doi.org/10.1111/1748-8583.12132

Černe, M., Nerstad, C. G., Dysvik, A., \& Škerlavaj, M. (2014). What goes around comes around: Knowledge hiding, perceived motivational climate, and creativity. Academy of Management Journal, 57(1), 172-192.

https://doi.org/10.5465/amj.2012.0122

Cheung, G. W., \& Lau, R. S. (2017). Accuracy of parameter estimates and confidence intervals in moderated mediation models: A comparison of regression and latent moderated structural equations. Organizational Research Methods, 20 (4), 746-769.

https://doi.org/10.1177/1094428115595869

Chiaburu, D. S., \& Harrison, D. A. (2008). Do peers make the place? conceptual synthesis and meta-analysis of coworker effects on perceptions, attitudes, OCBs, and performance. Journal of Applied Psychology, 93(5), 1082-1103. https://doi.org/10.1037/0021-9010.93.5.1082

Choi, B. G. (2002). Eliminate the internal enemies blocking the sharing of knowledge. $L G$ Economic Research Institute Weekly Report, 698. http://www.lgeri.com/report/view.do?idx = 1783

Connelly, C. E., Černe, M., Dysvik, A., \& Škerlavaj, M. (2019). Understanding knowledge hiding in organizations. Journal of Organizational Behavior, 4Q(7), 779-782. https://doi.org/10.1002/job.2407

Connelly, C. E., \& Zweig, D. (2015). How perpetrators and targets construe knowledge hiding in organizations. European Journal of Work and Organizational Psychology, 24(3), 479-489.

https://doi.org/10.1080/1359432x.2014.931325

Connelly, C. E., Zweig, D., Webster, J., \& Trougakos, J. P. (2012). Knowledge hiding in organizations. Journal of Organizational Behavior, 33(1), 64-88.

https://doi.org/10.1002/job.737

Demirkasimoglu, N. (2016). Knowledge hiding in academia: is personality a key factor?. International Journal of Higher Education, 5(1), 128-140.

Dollard, J., Doob, L., Miller, N., Mowrer, O., \& Sears, R. (1939). Frustration and aggression. New Haven, CT: Yale University Press.

Dwivedi, R. S. (1983). Management by trust: a conceptual model. Group \& Organization Studies, 8(4), 375-405. https://doi.org/10.1037/10022-000

Emmons, R. A. (1987). Narcissism: theory and measurement. Journal of Personality and Social Psychology, 52(1), 11-17. https://doi.org/10.1037/0022-3514.52.1.11

Exline, J. J., Baumeister, R. F., Bushman, B. J., Campbell, W. K., \& Finkel, E. J. (2004). Too proud to let go: Narcissistic entitlement as a barrier to forgiveness. Journal of Personality and Social Psychology, 876), 894-912. https://doi.org/10.1037/0022-3514.87.6.894

Ferris, G. R., \& Mitchell, T. R. (1987). The component of social influence and their importance for human resources research. In K. M. Rowland \& G. R. Ferris, (Eds.), Research in personnel and human resources management. Greenwich, CT: 
JAI Press.

Festinger, L. (1954). A theory of social comparison processes. Human Relations, 7(2), 117-140. https://doi.org/10.1177/001872675400700202

Flamholtz, E. (1979). Organizational control systems as a managerial tool. California Management Review, 22(2), 50-59.

https://doi.org/10.2307/41165320

Flynn, F. J., \& Brockner, J. (2003). It's different to give than to receive: predictors of givers' and receivers' reactions to favor exchange. Journal of Applied Psychology, 88(6), 1034-1045.

Gallucci, M., \& Perugini, M. (2003). Information seeking and reciprocity: a transformational analysis. European Journal of Social Psychology, 33(4), 473-495.

https://doi.org/10.1002/ejsp.156

Gouldner, A. W. (1960). The norm of reciprocity: A preliminary statement. American Sociological Review, 25(1), 161-178. https://doi.org/10.2307/2092623

Halbesleben, J. R. (2006). Sources of social support and burnout: a meta-analytic test of the conservation of resources model. Journal of Applied Psychology, 91(5), 1134-1145. https://doi.org/10.1037/0021-9010.91.5.1134

Harvey, P., \& Harris, K. J. (2010). Frustrationbased outcomes of entitlement and the influence of supervisor communication. Human Relations, 63(11), 1639-1660.

https://doi.org/10.1177/0018726710362923

Harvey, P., Harris, K. J., Gillis, W. E., \& Martinko, M. J. (2014). Abusive supervision and the entitled employee. The Leadership Quarterly, 25(2), 204-217. https://doi.org/10.1016/j.leaqua.2013.08.001

Harvey, P., \& Martinko, M. J. (2009). An empirical examination of the role of attributions in psychological entitlement and its outcomes. Journal of Organizational Behavior, 304), 459-476. https://doi.org/10.1002/job.549

Hernaus, T., Cerne, M., Connelly, C., Vokic, N. P., \& Škerlavaj, M. (2019). Evasive knowledge hiding in academia: when competitive individuals are asked to collaborate. Journal of Knowledge Management. 23(4), 597-618. https://doi.org/10.1108/JKM-11-2017-0531

Higgins, E. T. (1997). Beyond pleasure and pain. American Psychologist, 52(12), 1280-1300. https://doi.org/10.1037/0003-066X.52.12.1280

Hu, L. T., \& Bentler, P. M. (1999). Cutoff criteria for fit indexes in covariance structure analysis: conventional criteria versus new alternatives Structural Equation Modeling: A Multidisciplinary Journal, G(1), 1-55.

https://doi.org/10.1080/10705519909540118

Irum, A., Ghosh, K., \& Pandey, A. (2020). Workplace incivility and knowledge hiding: A research agenda. Benchmarking: An International Journal, 273), 958-980. https://doi.org/10.1108/BIJ-05-2019-0213

Jarvenpaa, S. L., \& Majchrzak, A. (2008). Knowledge collaboration among professionals protecting national security: role of transactive memories in ego-centered knowledge networks. Organization Science, 19(2), 260-276. https://doi.org/10.1287/orsc.1070.0315

Jones, W. H., Briggs, S. R., \& Smith, T. G. (1986). Shyness: conceptualization and 
measurement. Journal of Personality and Social Psychology, 51(3), 629-639.

https://doi.org/10.1037/0022-3514.51.3.629

Joiner, T. E. (2005). Why people die by suicide. Cambridge, MA: Harvard University Press.

Kaplan, E. M., \& Cowen, E. L. (1981). Interpersonal helping behavior of industrial foremen. Journal of Applied Psychology, 66(5), 633-638.

https://doi.org/10.1037/0021-9010.66.5.633

Kalshoven, K., \& Boon, C. T. (2012). Ethical leadership, employee well-being, and helping. Journal of Personnel Psychology, 11(1), 60-68. https://doi.org/10.1027/1866-5888/a000056

Kark, R., \& Van Dijk, D. (2007). Motivation to lead, motivation to follow: The role of the self-regulatory focus in leadership processes. Academy of Management Review, 32(2), 500-528. https://doi.org/10.5465/amr.2007.24351846

Kelley, H. H. (1973). The processes of causal attribution. American Psychologist, 28(2), 107-109.

https://doi.org/10.1037/h0034225

Khalid, M., Bashir, S., Khan, A. K., \& Abbas, N. (2018). When and how abusive supervision leads to knowledge hiding behaviors. Leadership \& Organization Development Journal, 396), 794-806.

https://doi.org/10.1108/LODJ-05-2017-0140

Kim, S. Y. (2016). Basic and extension of structural equation model. Seoul: hakjisa.

Ko, Y., \& Yoo, T. (2020). Development and validation of knowledge hiding motivation scale. Korean Journal of Industrial and Organizational Psychology, 33(1), 61 - 92. https://doi.org/10.24230/kjiop.v33i1.61-92

Komaki, J. L. (1986). Toward effective supervision: an operant analysis and comparison of managers at work. Journal of Applied Psychology, 71(2), 270-279.

https://doi.org/10.1037/0021-9010.71.2.270

Komaki, J. L., Desselles, M. L., \& Bowman, E. D. (1989). Definitely not a breeze: Extending an operant model of effective supervision to teams. Journal of Applied Psychology, 74(3), 522-529.

https://doi.org/10.1037/0021-9010.74.3.522

Komaki, J. L., Zlotnick, S., \& Jensen, M. (1986). Development of an operant-based taxonomy and observational index of supervisory behavior. Journal of Applied Psychology, 71(2), 260-269.

https://doi.org/10.1037/0021-9010.71.2.260

Larson, J. R., \& Callahan, C. (1990). Performance monitoring: How it affects work productivity. Journal of Applied Psychology, 75(5), 530-538. https://doi.org/10.1037/0021-9010.75.5.530

Lee, H. K. (2018). Analysis of the mediating effect, moderating effect, and moderated mediation effect using mplus. Paju, GG: Shinyoungsa.

Levine, D. P. (2005). The corrupt organization. Human Relations, 58(6), 723-740.

Lind, E. A. (2001). Fairness heuristic theory: justice judgments as pivotal cognitions in organizational relations. advances in organizational justice, Redwood City, CF: Stanford University Press.

Luthans, E., Hodgetts, R. M., \& Rosenkrantz, S. A. (1988). Real Managers. Cambridge, MA: Ballinger.

Malik, O. F., Shahzad, A., Raziq, M. M., Khan, 
M. M., Yusaf, S., \& Khan, A. (2019). Perceptions of organizational politics, knowledge hiding, and employee creativity: the moderating role of professional commitment. Personality and Individual Differences, 142(1), 232-237.

https://doi.org/10.1016/j.paid.2018.05.005

McAllister, D. J. (1995). Affect-and cognition-based trust as foundations for interpersonal cooperation in organizations. Academy of Management Journal, 38(1), 24-59.

https://doi.org/10.5465/256727

Milgram, N. N., Mey-Tal, G., \& Levison, Y. (1998). Procrastination, generalized or specific, in college students and their parents. Personality and Individual Differences, 25(2), 297-316.

https://doi.org/10.1016/S0191-8869(98)00044-0

Mitchell, M. S., \& Ambrose, M. L. (2007). Abusive supervision and workplace deviance and the moderating effects of negative reciprocity beliefs. Journal of Applied Psychology, 92(4), 1159-1168.

https://doi.org/10.1037/0021-9010.92.4.1159

Niehoff, B. P., \& Moorman, R. H. (1993). Justice as a mediator of the relationship between methods of monitoring and organizational citizenship behavior. Academy of Management Journal, 36(3), 527-556. https://doi.org/10.5465/256591

Oh, C. T. (2020). The simple mediating effect of work engagement and the simple moderating effect and the moderated mediating effect of organizational embeddedness in the relationships among social worker's perceived organizational support, work engagement, personal initiative, and organizational embeddedness, Academy of Korean Social Welfare Administration, 22(1), 45-71.

Ohbuchi, K. I., \& Fukushima, O. (1997). Personality and interpersonal conflict: Aggressiveness, self monitoring, and situational variables. International Journal of Conflict Management, 8(2), 99-113. https://doi.org/10.1177/0022022199030001003

Park, H., Lee, S., Son, S., Kim, S., \& Yun, S. (2011). The effects of organizational justice on the knowledge sharing of subordinates. Korean Management Review, 40(2), 485-521.

Peng, H. (2013). Why and when do people hide knowledge? Journal of Knowledge Management, 17(3), 398-415.

Perugini, M., Gallucci, M., Presaghi, F., \& Ercolani, A. P. (2003). The personal norm of reciprocity. European Journal of Personality, 17(4), 251-283. https://doi.org/10.1002/per.474

Pierce, J. L. \& Jussila, I. (2010). Collective psychological ownership within the work and organizational context: Construct introduction and elaboration. Journal of Organizational Behavior, 31(6), 810-834. https://doi.org/10.1002/job.628

Pierce, J. L., Kostova, T. \& Dirks, K. T. (2001), Toward a theory of psychological ownership in organizations. Academy of Management Review, 26(2), 298-310. https://doi.org/10.5465/amr.2001.4378028

Reidy, D. E., Zeichner, A., Foster, J. D., \& Martinez, M. A. (2008). Effects of narcissistic 
entitlement and exploitativeness on human

physical aggression. Personality and Individual

Differences, 44(4), 865-875.

https://doi.org/10.1016/j.paid.2007.10.015

Rhee, Y. W., \& Choi, J. N. (2017). Knowledge management behavior and individual creativity: Goal orientations as antecedents and in group social status as moderating contingency. Journal of Organizational Behavior, 38(6), 813-832.

https://doi.org/10.1002/job.2168

Sardeshmukh, S. R., \& Vandenberg, R. J. (2017). Integrating moderation and mediation: $\mathrm{A}$ structural equation modeling approach. Organizational Research Methods, 204), 721-745. https://doi.org/10.1177/1094428115621609

Scott, S. G., \& Bruce, R. A. (1994). Determinants of innovative behavior: A path model of individual innovation in the workplace. Academy of Management Journal, 373), 580-607. https://doi.org/10.5465/256701

Serenko, A., \& Bontis, N. (2016). Understanding counterproductive knowledge behavior: antecedents and consequences of intraorganizational knowledge hiding. Journal of Knowledge Management, 2066), 1199-1224. https://doi.org/10.1108/JKM-05-2016-0203

Snow, J. N., Kern, R. M., \& Curlette, W. L. (2001). Identifying personality traits associated with attrition in systematic training for effective parenting groups. The Family Journal, (2), 102-108.

https://doi.org/10.1177/1066480701092003

Spender, J. C., \& Grant, R. M. (1996). Knowledge and the firm: overview. Strategic Management
Journal, 17(S2), 5-9.

https://doi.org/10.1002/smj.4250171103

Stanton, J. M. (2000). Reactions to employee performance monitoring: Framework, review, and research directions. Human Performance, 13(1), 85-113. https://doi.org/10.1207/S15327043HUP1301_4

Tang, P. M., Bavik, Y. L., Chen, Y., \& Tjosvold, D. (2015). Linking ethical leadership to knowledge sharing and knowledge hiding: The mediating role of psychological engagement. International Proceedings of Economics Development and Research, 84, 71-76.

https://commons. ln.edu.hk/sw_master/3640

Tangirala, S., \& Ramanujam, R. (2008). Employee silence on critical work issues: The cross level effects of procedural justice climate. Personnel Psychology, 61(1), 37-68.

https://doi.org/10.1111/j.1744-6570.2008.00105.x

Tyler, T. R., \& Lind, E. A. (1992). A relational model of authority in groups. In advances in experimental social psychology. Cambridge, MA: Academic Press.

Viswesvaran, C., Sanchez, J. I., \& Fisher, J. (1999). The role of social support in the process of work stress: a meta-analysis. Journal of Vocational Behavior, 54(2), 314-334. https://doi.org/10.1006/jvbe.1998.1661

Walster, E., Berscheid, E., \& Walster, G. W. (1973). New directions in equity research. Journal of Personality and Social Psychology, 25(2), 151-176. https://doi.org/10.1016/S0065-2601(08)60057-X

Wang, S., \& Noe, R. A. (2010). Knowledge sharing: A review and directions for future 
research. Human Resource Management Review, 20(2), 115-131.

https://doi.org/10.1016/j.hrmr.2009.10.001

Watson, D., \& Friend, R. (1969). Measurement of social-evaluative anxiety. Journal of Consulting and Clinical Psychology, 33(4), 448-457. https://doi.org/10.1037/h0027806

Weiner, B. (2004). Social motivation and moral emotions: an attributional perspective. In M. J. Martinko (Ed.), Attribution theory in the organizational sciences. Greenwhich, CT: Information Age Publishing.

Yao, Z., Luo, J., \& Zhang, X. (2020). Gossip is a fearful thing: the impact of negative workplace gossip on knowledge hiding. Journal of Knowledge Management, 24(7), 1755-1775. https://doi.org/10.1108/JKM-04-2020-0264
Yukl, G. (1989). Managerial leadership: A review of theory and research. Journal of Management, 15(2), 251-289. https://doi.org/10.1177/014920638901500207

Zhou, J. (2003). When the presence of creative coworkers is related to creativity: Role of supervisor close monitoring, developmental feedback, and creative personality. Journal of Applied Psychology, 88(3), 413-422. https://doi.org/10.1037/0021-9010.88.3.413
투고일자 : 2021. 09. 21 수정일자 : 2022. 01.06 게재확정 : 2022. 01. 24 


\section{The mediation effects of knowledge hiding motivations between knowledge requester's psychological entitlement and knowledge hiding and the moderated mediation effect of supervisor monitoring}

Kwangwoon University

The purpose of this study is to examine the mediation effects of knowledge hiding motivations(personal ownership, fear of loss, concern for negative evaluation, and negative relation) between the knowledge requester's psychological entitlement and knowledge hiding. Also, the purpose of this study is to examine the moderated mediation effect of supervisor monitoring on the mediating effects of knowledge hiding motivations. For the study, the survey was conducted on 400 employees working at various companies in Korea. According to the data analysis, knowledge hiding motivations(personal ownership, fear of loss, and concern for negative evaluation) had mediating effects between the knowledge requester's psychological entitlement and knowledge hiding. But, negative relation motivation had no significant mediating effect. The supervisor monitoring moderated the mediating effects of knowledge hiding motivations(personal ownership, fear of loss motivation) between the knowledge requester's psychological entitlement and knowledge hiding. But, concern for negative evaluation motivation and negative relation motivation had no significant moderated mediation effects. This study is expected to provide important implications for practitioners about the mediating effects of knowledge hiding motivation and the moderated mediating effects of supervisor monitoring.

Key words : knowledge hiding, knowledge hiding motivation, psychological entitlement, supervisor monitoring 